\title{
The effect of climate change on agro-climatic indicators in the UK
}

\author{
N. W. Arnell ${ }^{1}$ (D) A. Freeman ${ }^{1}$
}

Received: 16 September 2020 / Accepted: 2 March 2021 / Published online: 31 March 2021

(C) The Author(s) 2021

\begin{abstract}
The effect of climate change on agriculture in the UK is here assessed using a comprehensive series of policy-relevant agro-climate indicators characterising changes to climate resources and hazards affecting productivity and operations. This paper presents projections of these indicators across the UK with gridded observed data and UKCP18 climate projections representing a range of greenhouse gas emissions scenarios. The projections can be used to inform climate change mitigation and adaptation policy. There will be substantial changes in the climate resource and hazard across the UK during the twentyfirst century if emissions continue to follow a high trajectory, and there will still be some changes if emissions reduce to achieve international climate policy targets. Growing seasons for certain crops will lengthen, crop growth will be accelerated, and both drought and heat risks (for some types of production) will increase. Soils will become drier in autumn, although there will be less change in winter and spring. The longer growing seasons and warmer temperatures provide opportunities for new crops, subject to the effects of increasing challenges to production. Most of the changes are relatively consistent across the UK, although drought risk and heat stress risk increase most rapidly in the south and east. The climate change trend is superimposed onto considerable year to year variability. Although there is strong consensus across climate projections on the direction of change, there is considerable uncertainty in the rate and magnitude of change for a given emissions scenario. For the temperature-based indicators, this reflects uncertainty in climate sensitivity, whilst for the precipitation-based indicators largely reflects uncertainty in projected changes in the weather systems affecting the UK.
\end{abstract}

Keywords Climate impacts $\cdot$ Agriculture $\cdot$ UKCP18 $\cdot$ Drought $\cdot$ Heat impacts

N. W. Arnell

n.w.arnell@ reading.ac.uk

1 Department of Meteorology, University of Reading, Reading, UK 


\section{Introduction}

In August 2020, the Times newspaper published a news article entitled 'Climate forces farms to start growing soya'. A wet winter and dry summer had led to 'the worst wheat harvest in decades', but some farmers had begun growing soya, a crop which needs higher temperatures than typically expected in the UK. This encapsulates the potential effect of climate change on agriculture in the UK: changes in the potential for crop and livestock production, but changes too in the likelihood of challenging weather events affecting both operations and crop growth.

Agricultural land covers $72 \%$ of the UK (Defra 2020a), divided almost equally between cropland (wheat and barley being the most common crops), improved pasture and rough grazing. The agri-food sector as a whole employs 3.6 million people and contributes around $6 \%$ to the UK's GVA, although the agricultural sector itself contributes less than $1 \%$ of the UK's GDP and directly employs around 476 thousand people (Defra 2020a). The Second UK Climate Change Risk Assessment (CCRA2) highlighted the sensitivity of UK agriculture to climate change (Brown et al. 2016), potentially affecting not only agricultural production and businesses but also the management, biodiversity, and cultural value of landscapes across large parts of the UK.

Climate change due to an increasing concentration of greenhouse gases has three broad effects on crop and livestock productivity (see also Olesen and Bindi 2002; Deryng et al. 2014; Trnka et al. 2014; Gobin 2018). First, the climate regime at a place (its mean and variability) affects what could or could not be grown and what measures are needed — such as irrigation - to support production: this can be seen as the climate resource (Stehr and von Storch 2009; Selvaraju et al. 2011). A change in climate regime potentially alters these climate resources, making some types of production less viable but enabling others. Meanwhile, increases in atmospheric carbon dioxide concentrations can lead to increased productivity of some crops (including grass, wheat, and barley), but changes in climate may adversely affect soil nutrients and fertility and weed growth will also be affected. Changes to climate regime will potentially therefore affect farmer decisions on what to produce and what infrastructure is needed to support that production. What the farmer actually plants or produces, however, is also influenced by agro-economic policy, national and international food markets, and anticipated prices.

Second, extreme events during the growing season can result in reduced or lost production. For example, drought or high temperatures at critical times can stress crops and livestock. Flooding, heavy rain, and hail (currently rare in the UK) can damage crops. High temperatures accelerate crop growth and development stages, potentially leading to lower yields (Craufurd and Wheeler 2008). Outbreaks of pests, parasites, and diseases may be triggered or facilitated by weather conditions.

Third, weather may affect operations such as access to fields, planting, and harvesting. For example, prolonged wet conditions in winter and spring may prevent farmers from accessing land with machinery or moving livestock into fields from winter accommodation.

In principle, it is possible to estimate the effects of climate change on crop and livestock production by modelling all these drivers. However, this is not only computationally difficult (for example, it would be necessary to construct and apply models for all potential crops and livestock systems) but also conceptually challenging because farmer decisions may determine the impacts of climate change. These farmer decisions will be based partly on perceptions of changing conditions on the farm, but partly on national and international markets and policy changes, and on the dissemination of innovation. An alternative approach is therefore to characterise the potential effects of climate change on agriculture through a suite of climatebased indicators ('agro-climate indicators'; Trnka et al. 2010; Hatfield et al. 2020; Walsh et al. 2020). Such indicators are proxies for the effects of weather and climate on specific 
agricultural activities, but do not directly quantify themselves effects on, for example, productivity, animal welfare, or specific agricultural operations.

This paper presents a series of agro-climatic indicators which characterise the potential effects of climate change on agriculture in the UK. The indicators are taken from the literature (Knox et al. 2010; Rivington et al. 2013; Harding et al. 2015; Parsons et al. 2019; Bachmair et al. 2018; Dunn et al. 2014; Jones et al. 2020), are relevant to stakeholders (e.g. Matthews et al. 2008), and are directly linked to weather impacts. They cover changes to the climate resource, climate hazard, and agricultural operations, for both food and forage crops and livestock. They are calculated across the UK, using a consistent set of observed climate data and UKCP18 climate projections (Lowe et al. 2018). The paper calculates 'worst case' projections under high emissions and considers the effects of international efforts to reduce greenhouse gas emissions, and shows the variations in impact across the UK. It is designed to inform strategic level assessments of the effect of climate change on agriculture in the UK, both to support the development of high-level climate policy and to support strategies to enhance adaptation and resilience in the agriculture sector. The paper presents results produced as part of a broader multi-sectoral evaluation of policy-relevant indicators of climate change in the UK (Arnell et al. 2021). CCRA2 concluded that more research was needed into the nature and scale of changing land suitability and its impacts (Brown et al. 2016): this paper addresses this gap.

Section 2 describes the agro-climate indicators used in this study, together with the climate projections. Section 3 presents, for context, the current (1981-2010) geographical distribution of these indicators. Changes in the indicators by region and nation with high emissions and the effects of reductions in emissions are presented in Section 4. Section 5 discusses implications for UK agriculture and draws some general conclusions.

There have so far been few published UK-scale general analyses of the effect of climate change on agricultural systems. Harding et al. (2015) calculated five agro-climate indicators across the UK, and Fezzi et al. (2014) used an empirical econometric model with growing season temperature and precipitation to estimate change in the relative distributions of grassland and cereal crops across the UK: Ritchie et al. (2019) applied the same model with different climate scenarios across Great Britain. Rivington et al. (2013) calculated indicators across Scotland. Warmer temperatures would suggest an increase in the proportion of agricultural land in England and Wales (Keay et al. 2013) and Scotland (Brown et al. 2011) in the highest land capability class, but that this would be more than offset by reductions in capability due to increased drought. Other national-scale studies have looked at specific crops (including wheat (Semenov 2009; Cho et al. 2012; Harkness et al. 2020), grassland (Qi et al. 2018), barley (Yawson et al. 2016), and potatoes (Daccache et al. 2012)) or livestock systems (Dunn et al. 2014; Fodor et al. 2018). Taken together, these studies project an increase in growing season length and growing degree days, an increase in potential productivity for wheat, barley, and for grassland-primarily due to an increase in atmospheric $\mathrm{CO}_{2}$ concentrations - but increasing effects of summer drought on wheat and potato (and by implication other seasonal vegetables) and increasing heat stress for livestock.

\section{Agro-climate indicators, data, and climate projections}

\subsection{Overall approach}

The effect of climate change on agriculture in the UK is characterised by a series of agroclimate indicators, using 12×12-km gridded observed daily climate data for 1981-2010 and 
UKCP18 climate projections applied using the delta method. Results are aggregated to the regional level (Fig. 1), weighted by area of agricultural land.

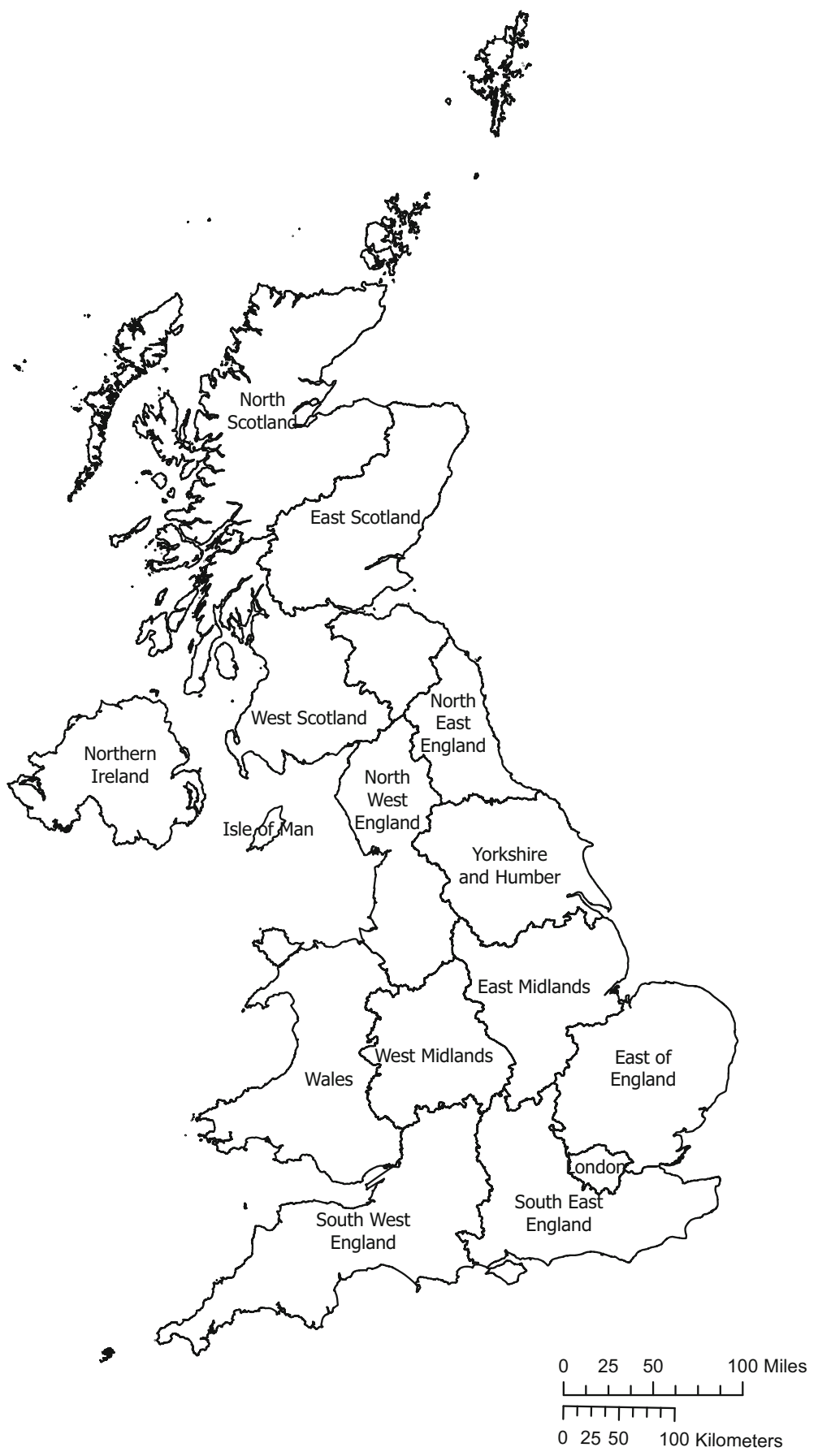

Fig. 1 UK regions 


\subsection{Agro-climate indicators}

Table 1 summarises the agro-climate indicators used here, separated into indicators characterising the climate resource, agricultural operations, and climate hazards - although the boundaries between the three categories are not sharp. The indicators are described in more detail in Supplementary Material. All are calculated from daily weather data to produce time series of annual totals or accumulations.

The thermal growing season starts when average temperatures exceed $5.6^{\circ} \mathrm{C}$, and growing season length is the time from the start of the thermal growing season to when average temperatures fall below $5.6{ }^{\circ} \mathrm{C}$. Plant phenological development is, in the absence of other constraints on water and nutrient availability, determined by accumulated temperature above $5.6{ }^{\circ} \mathrm{C}$ as measured by growing degree days. This may be restricted on days with high temperature, but no upper limit is imposed here, and this analysis uses the same algorithm for calculating growing degree days as used by Kendon et al. (2019a). The productivity of perennial crops - such as grassland - is directly linked to growing degree days, in the absence

Table 1 Summary of the agri-climate indicators

\begin{tabular}{|c|c|c|}
\hline Indicator & Definition & Reference \\
\hline \multicolumn{3}{|l|}{ Climate resource } \\
\hline Start of growing season & $\begin{array}{l}\text { The first of five consecutive days with average } \\
\text { temperature }>5.6^{\circ} \mathrm{C} \text { (day of year) }\end{array}$ & $\begin{array}{l}\text { Rivington et al. (2013) } \\
\text { Harding et al. (2015) }\end{array}$ \\
\hline Growing season length & $\begin{array}{l}\text { Days between start of growing season and first } \\
\text { of five consecutive days with average } \\
\text { temperature }<5.6^{\circ} \mathrm{C} \text { (days) }\end{array}$ & $\begin{array}{l}\text { Rivington et al. (2013) } \\
\text { Harding et al. (2015) }\end{array}$ \\
\hline Growing degree days & $\begin{array}{l}\text { Sum of average temperatures above } 5.6{ }^{\circ} \mathrm{C} \\
\left({ }^{\circ} \mathrm{C} \text {-days }\right)\end{array}$ & Rivington et al. (2013) \\
\hline Potential soil moisture deficit & $\begin{array}{l}\text { Annual maximum potential soil moisture } \\
\text { deficit, calculated from potential } \\
\text { evaporation minus precipitation }\end{array}$ & $\begin{array}{l}\text { Knox et al. (2010) } \\
\text { Daccache et al. (2012) }\end{array}$ \\
\hline \multicolumn{3}{|l|}{ Agricultural operations } \\
\hline Start of field operations & $\begin{array}{l}\text { Day when accumulated average temperature } \\
\text { from January } 1 \text { st exceeds } 200^{\circ} \mathrm{C} \\
\text { (day of year) }\end{array}$ & $\begin{array}{l}\text { Rivington et al. (2013) } \\
\text { Harding et al. (2015) }\end{array}$ \\
\hline Wet soils & $\begin{array}{l}\text { Days with soil moisture at or above field } \\
\text { capacity (days/year) }\end{array}$ & \\
\hline \multicolumn{3}{|l|}{ Climate hazard } \\
\hline SPEI severe drought & $\begin{array}{l}\text { Time with 6-month Standardised Precipitation } \\
\text { Evaporation Index }<-1.5 \text { (proportion of time) }\end{array}$ & Parsons et al. (2019) \\
\hline SPI severe drought & $\begin{array}{l}\text { Time with } 3 \text {-month Standardised Precipitation } \\
\text { Index }<-1.5 \text { (proportion of time) }\end{array}$ & Bachmair et al. (2018) \\
\hline Crop growth duration & $\begin{array}{l}\text { Days to accumulate reference period Growing } \\
\text { Degree Days (days) }\end{array}$ & \\
\hline Frost days & $\begin{array}{l}\text { Days with minimum temperature }<0{ }^{\circ} \mathrm{C} \\
\text { (days/year) }\end{array}$ & Rivington et al. (2013) \\
\hline Accumulated frost & $\begin{array}{l}\text { Sum of minimum temperatures below } 0^{\circ} \mathrm{C} \\
\left({ }^{\circ} \mathrm{C} \text {-days }\right)\end{array}$ & $\begin{array}{l}\text { Rivington et al. (2013) } \\
\text { Harding et al. (2015) }\end{array}$ \\
\hline Parasite outbreaks in sheep & $\begin{array}{l}\text { Days with average temperature }>9{ }^{\circ} \mathrm{C} \\
\text { (indent for consistency with other items in this } \\
\text { column) (days/year) }\end{array}$ & Jones et al. (2020) \\
\hline Heat stress effect on milk yield & $\begin{array}{l}\text { Days with temperature humidity index }>70 \\
\text { (days/year) }\end{array}$ & Dunn et al. (2014) \\
\hline Heat stress during wheat anthesis & $\begin{array}{l}\text { Days with maximum temperature }>32{ }^{\circ} \mathrm{C} \\
\text { between } 1 \text { May and } 15 \text { June (days/year) }\end{array}$ & Jones et al. (2020) \\
\hline
\end{tabular}


of other constraints on growth. The total number of growing degree days influences which annual crops could feasibly be planted. The potential soil moisture deficit (PSMD) is a measure of crop demand for water and hence the potential need for supplemental irrigation. It is calculated as the largest cumulative difference during the year between potential evaporation and rainfall (Knox et al. 2010; Daccache et al. 2012). The climatic suitability of land for agriculture is often based on accumulated temperature and PSMD (e.g. Brown et al. 2011; Daccache et al. 2012; Keay et al. 2013).

The start of field operations indicator is a proxy for the earliest date in the year when a field might be usefully worked (Harding et al. 2015): an accumulated thermal sum of $200{ }^{\circ} \mathrm{C}$ (Tsum200) is commonly used by farmers as a rule of thumb for when to apply fertiliser to grass, for example. If soils are wet, then farmers cannot use machinery or put livestock into fields. This is characterised here by the number of days when soil moisture is at or above field capacity, calculated using a simple daily water balance model assuming a constant welldrained clay-loam soil with fixed field capacity across the UK (see Supplementary Material for a sensitivity analysis for other soil properties). Again, this informs the capability of land for agriculture (Keay et al. 2013).

Farmer decisions on what and when to plant are influenced by anticipated climate resource and operational conditions, and perceptions of the chance of damaging events. Once decisions are made, the productivity of crops and livestock will depend on actual growing conditions and the occurrence of damaging events. Lack of water is characterised by two drought indicators. The Standardised Precipitation Index (SPI; McKee et al. 1993) is based on precipitation totals accumulated over 3 months (SPI-3), following Bachmair et al. (2018). The Standardised Precipitation Evaporation Index (SPEI; Vicente-Serrano et al. 2010) is based on the difference between precipitation and potential evaporation accumulated over 6 months (SPEI-6), following Parsons et al. (2019). Both indicators are calculated by standardising the accumulated time series over a specific reference period, here 1981-2010, and critical thresholds determined empirically rather than using a fitted theoretical distribution. In each case, the indicator is the proportion of time with an index value below a threshold value of -1.5 , which occurs by definition $6.7 \%$ of the time over the reference period (or for 24 out of the 360 months). Both drought indicators are associated with agricultural impacts in the UK (Haro-Monteaguodo et al. 2017; Bachmair et al. 2018; Parsons et al. 2019).

High temperatures can limit growth (and at the extreme kill plants) and cause discomfort to livestock, but the critical thresholds vary between crops and animals and vary through the year. Two illustrative heat-stress indicators are calculated here. One is the number of days during the anthesis (flowering and seed setting) stage for wheat when maximum temperature exceeds $32{ }^{\circ} \mathrm{C}$ (Jones et al. 2020): anthesis is assumed to occur between 1 May and 15 June. Grain yield reduces by at least $10 \%$ for each day during anthesis that temperature exceeds $32{ }^{\circ} \mathrm{C}$. The other characterises the effect of high temperatures on dairy cattle milk yield (Dunn et al. 2014; Fodor et al. 2018; Jones et al. 2020). Here, this is represented by the number of days the temperature humidity index (THI) exceeds 70 . THI is calculated from daily average temperature and relative humidity. Milk yield falls linearly with increase in THI above 70 (which is equivalent to an average temperature of around $21{ }^{\circ} \mathrm{C}$ with a typical relative humidity of $75 \%$ ). At the other extreme, cold days can hinder growth - although some crops (such as apples) require periods of low temperatures at critical development stages. The number of cold days is here characterised by the number of days with minimum temperatures below $0{ }^{\circ} \mathrm{C}$ (air frost).

Annual crops need to accumulate specific numbers of degree days to reach specific growth stages, but if these stages are reached too quickly, then yields are reduced (Craufurd \& 
Wheeler \& 2008; Hatfield et al. 2011). This is characterised here by the time taken in a year to accumulate the average reference period (1981-2010) growing degree days: a reduction in crop growth duration implies a reduction in yield compared to the average expectation.

Finally, productivity can be affected by pests, parasites, and disease. The accumulated frost indicator measures the severity of winter and is a proxy for the likelihood that pests survive over winter (Harding et al. 2015): the more negative the indicator, the lower the likelihood that pests survive. It is specifically based on data from aphids affecting cereal crops (Dewar and Carter 1984). A second indicator characterises parasite outbreaks in sheep (Jones et al. 2020). The number of days with average temperature above $9{ }^{\circ} \mathrm{C}$ is an indicator of the potential number of life cycles of one of the most significant gastro-intestinal parasites (Haemonchus contortus) causing ill-health and malnourishment in sheep (Jones et al. 2020).

Climate change will affect the mean and the year-to-year variability in these indicators. Different agricultural stakeholders will have different priorities for information on how the indicators will change. Some may be interested in projected changes in the mean, whilst others might be more concerned by changes in the chance of experiencing some critical event or season. Some want to get an idea of the general direction and significance of climate change, and others are more concerned about planning to enhance resilience. There are therefore several different ways of presenting how climate change will affect agro-climate indicators, and some involve defining critical thresholds representing a 'significant' change. The analysis here is primarily concerned with characterising the potential effects of climate change at a strategic level, and in itself is not intended to directly inform specific farm or industry adaptation actions to enhance resilience. With one exception, the analysis is therefore based on changes to long-term (30 years) mean values in the indicators, recognising both that any individual year may experience a value very different to the mean, and that changes in the mean may be small compared with year-to-year variability. The one exception is the wheat heat stress indicator, which is expressed as the chance of experiencing at least one heat stress day in a year. This is because heat stress days are very infrequent, the average annual number is not very meaningful, and the critical threshold is very clear (just 1 day above the threshold causes problems). For all the other indicators, thresholds defining critical change depend on context or degree of risk aversion.

The set of indicators presented here characterise many of the effects of weather and its variability on crop and livestock productivity. Other potential effects are not considered. These include the occurrence of late frosts, the effect of short-duration heavy rainfall on crops, the effects of river flooding, and the effect of hailstorms. The indicators also do not consider the effects of climate change on soil fertility or erosion, or the potential beneficial effects of increasing $\mathrm{CO}_{2}$ concentrations.

\subsection{Reference climate data}

Observed climate data were taken from HadUK-Grid 12-km resolution observational data set (Met Office 2018; Hollis et al. 2019), supplemented by ERA5 reanalysis (Copernicus Climate Change Service 2017). The HadUK-Grid $12 \mathrm{~km}$ data set includes daily minimum and maximum temperature and rainfall up to 2018, but sunshine hours, windspeed, and relative humidity (needed to estimate potential evaporation) are only available as monthly averages. Daily windspeed and relative humidity was therefore estimated from the ERA5 reanalysis, rescaling the ERA5 reanalysis so that the monthly mean equalled the HadUK-Grid monthly mean. The time period 1981-2010 is used to represent current climate. 


\subsection{Climate projections and their application}

The UKCP18 land climate projections (Lowe et al. 2018; Murphy et al. 2019) consist of four strands: global, regional, local, and probabilistic. The global strand comprises an ensemble of 15 climate projections at a spatial resolution of $60 \times 60 \mathrm{~km}$ made using variants of the HadGEM3 climate model and an ensemble of 12 projections made using CMIP5 climate models. Projections are made for two levels of climate forcing, representing high (RCP8.5) and low (RCP2.6) emissions. These projections each maintain realistic physical relationships between climate variables and coherent patterns of change across the UK. The regional strand is based on higher-resolution versions of HadGEM3, and in practice gives similar results to the global HadGEM3 projections. The local strand is a smaller number of even higher-resolution projections, and these were not applied. The probabilistic strand consists of an ensemble of 3000 equally plausible projections at four different levels of forcing, but these do not necessarily maintain realistic physical relationships between variables as represented by the global and regional models.

This paper focuses on the probabilistic projections with RCP2.6, RCP6.0, and RCP8.5 forcings, which have the global temperature increases summarised in Table 2. The indicators were also calculated with the global and regional strands, and are presented in Supplementary Material: important differences between these strands and the probabilistic strands are highlighted below.

Figure 2 shows regional average changes in seasonal temperature and rainfall with the three sets of forcings. Temperature increases in each season consistently across the UK. Rainfall tends to decrease in summer, particularly across the south and east, and increase in autumn and winter, particularly in the north and west. The direction of change in rainfall in spring is more uncertain. The changes are greatest with the higher emissions.

The climate projections to 2100 for monthly average temperature, precipitation, vapour pressure, cloud cover, and windspeed were applied to the gridded observed 1981-2010 daily time series using the delta method (see Supplementary Material). Each variable for a given ensemble member was first expressed as an anomaly from its 1981-2010 monthly mean (absolute for temperature, relative for the other variables). The individual probabilistic strand ensemble members do not necessarily have consistent changes in minimum and maximum temperatures, so changes in average temperature were applied to both minimum and maximum temperatures. The probabilistic projections also do not include windspeed, so this was assumed unchanged (this is only used in the calculation of potential evaporation, and leaving this unchanged has very little effect on changes in potential evaporation).

Table 2 Increases in global mean temperature with the RCP2.6, RCP6.0, and RCP8.5 projections

\begin{tabular}{llll}
\hline & \multicolumn{2}{l}{ Increase in temperature above pre-industrial levels $\left({ }^{\circ} \mathrm{C}\right)$} & \\
\cline { 2 - 4 } & $\mathrm{RCP} 2.6$ & $\mathrm{RCP} 6.0$ & $\mathrm{RCP} 8.5$ \\
\hline $2050 \mathrm{~s}$ & $1.6(1.1-2.2)$ & $1.7(1.3-2.2)$ & $2.3(1.7-2.9)$ \\
2100 & $1.9(1.3-2.6)$ & $3.7(2.8-4.7)$ & $5.1(4.0-6.5)$ \\
\hline
\end{tabular}

The table shows the median estimate of increase in global mean temperature, with the 10th to 90th percentile range in brackets. The average global temperature over the period $1981-2010$ was approximately $0.61{ }^{\circ} \mathrm{C}$ warmer than pre-industrial levels 


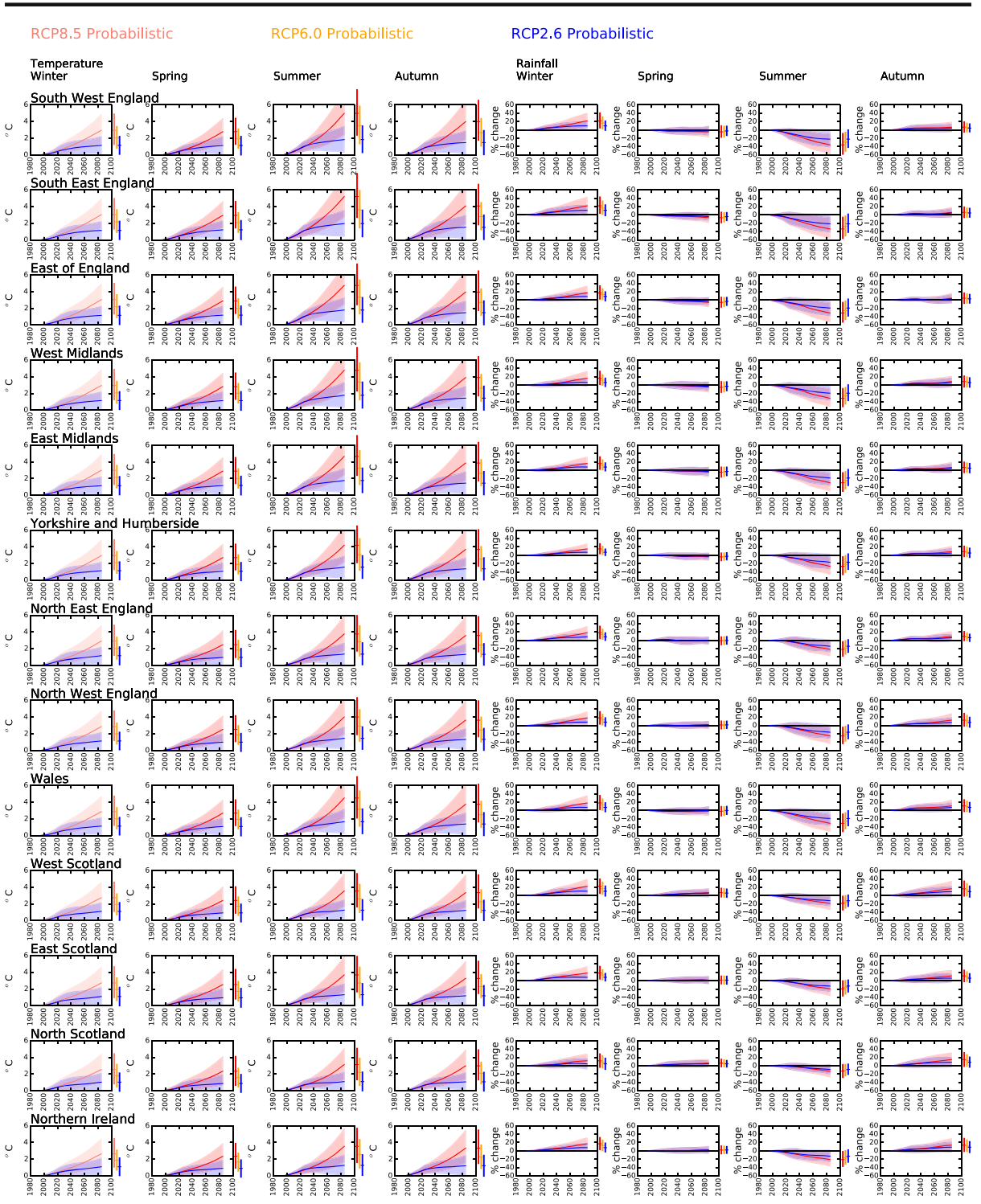

Fig. 2 Change in 30-year mean seasonal temperature and precipitation by region: UKCP18 probabilistic projections, RCP2.6, RCP6.0, and RCP8.5. The mean values are plotted at the central year of the 30-year period, and the plots show the median plus the 10th to 90th percentile ranges ('low' to 'high'). The bars on the right show the 2071-2100 mean

The resulting time series of monthly anomalies were then smoothed using a 31-year running mean to remove the effect of year-to-year variability and extract the climate change signal. In order to calculate anomalies for the last 15 years of the projections, the anomaly time series were extrapolated using linear regression. There can be large differences in anomaly from 1 month to the next - which introduces unrealistic steps at month boundaries - so the monthly anomalies were interpolated to the daily scale before being applied to the observed daily data. Time series of daily weather from 2011 to 2100 were constructed by repeating the 1981-2010 time series three times and applying the annual time series of anomalies. 
The UKCP18 projections comprise ensembles of projected time series of monthly or daily weather variables. These model time series include changes in both mean and variability, as simulated by the climate model, and could in principle be used directly to calculate the agroclimate indicators. Instead, this study uses the delta method as outlined above for three reasons. First, observed data is used to characterise the current climate because this observed experience is familiar to stakeholders. Second, some form of bias adjustment need to be applied to the UKCP18 model projections. Different bias adjustment approaches exist correcting for different aspects of bias, and all assume that the adjustments continue into the future. Third, it would have been impractical to test and apply bias adjustment methods which preserved relationships between variables for all projections and locations.

The delta method as applied here produces time series of daily weather which broadly maintain observed patterns of day to day and year to year variability. However, it assumes that relative variability in climate from year to year does not change into the future, and that the proportional change in a variable does not vary with the magnitude of that variable. Climate change could generate increased variability in summer temperatures from year to year (Kendon et al. 2019b), and this would increase the number of high temperature extremes. Similarly, a reduction in the number of wet days would increase the chance of prolonged dry spells, and an increase in the number of heavy precipitation events (Kendon et al. 2019a) could lead to an increase in short-duration soil water-logging. These potential effects are not incorporated here.

\subsection{Regional averages}

The agro-climate indicators are implemented at a spatial resolution of $12 \times 12 \mathrm{~km}$ across the UK. Regional averages are calculated for UK regions (8 in England (excluding London), 3 in Scotland, and Wales and Northern Ireland), weighting the grid cell values by the area of cropland and improved pasture taken from the 2015 UK Land Cover Map (CEH 2017). The PSMD and wheat heat stress indicators are weighted by cropland area only, and the livestock indicators were averaged over the area of improved pasture.

\section{Current values of the agro-climate indicators}

Figure 3 shows the geographical distribution of the resource, operational, and hazard agroclimate indicators with the observed 1981-2010 climate (except for the two drought indicators, which are by definition constant across the UK over the reference period, and the crop growth duration which is equal to the growing season length over the reference period). All maps show the average (or chance) calculated over the 30 -year period.

The spatial patterns largely reflect the variation in temperature across the UK. At present, the growing season typically starts in early March in southern England and by late April in upland areas. The growing season varies from over 250 days in the south to less than 200 in the uplands and parts of the north. Average annual maximum potential soil moisture deficit is greatest in the south and east.

The start of field operations is between mid-February and mid-March in southern England, and up to a month later in the uplands. The average number of days with soil moisture above field capacity (assuming here a clay-loam soil) ranges from less than 20 in eastern England to over 200 in parts of Scotland. South east England has around 50 frost days a year, and this 
Observed 1981-2010

Start of growing season Day of year

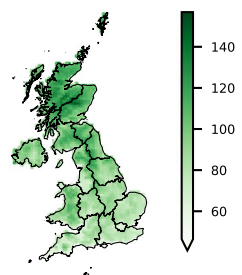

Growing season length Days

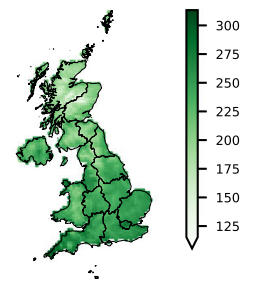

Days with

Start of field operations soil moisture $>$ field capacity Day of year

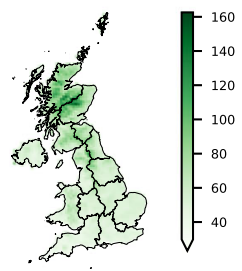

Accumulated frost ${ }^{\circ} \mathrm{C}$-days
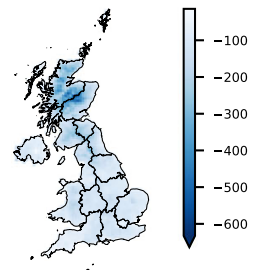

Frost days Days/year

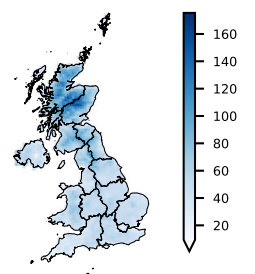

Days/year

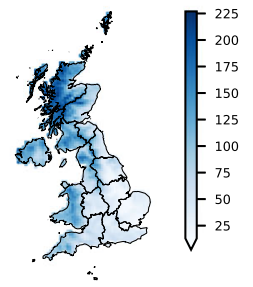

Sheep parasite danger Days/year

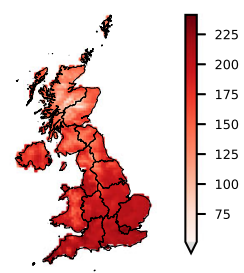

Growing degree days Potential Soil Moisture Deficit ${ }^{\circ} \mathrm{C}$-days
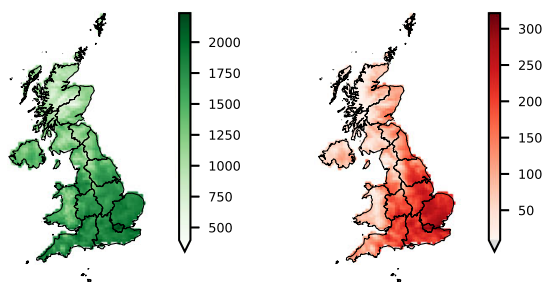

Milk yield: heat stress

Wheat heat stress (anthesis)

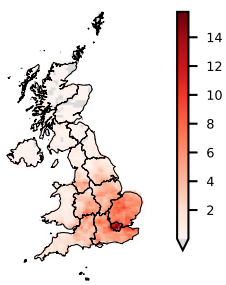

$\%$ chance

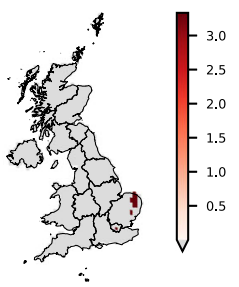

Fig. 3 The reference period (1981-2010) distribution of agro-climate indicators across the UK. The maps show the 30-year mean, and for the wheat heat stress indicator, the percentage of years between 1981 and 2010 with at least one heat stress day

increases to over 70 in the uplands. More than 200 days per year are suitable for sheep parasites in south east England, falling to under 150 in upland areas in the north and west. There were on average fewer than 3 or 4 days with potential heatrelated reductions in milk yield in south and east England, and far fewer in the west and north. Over the period 1981-2010, days with damaging high temperatures for wheat occurred just in 1996 in eastern England. 
RCP8.5 Probabilistic

Start of

Growing season

South West England

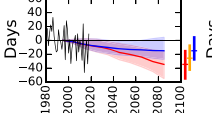

South East England

(1)

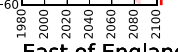

East of England

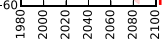

${ }_{60}$ West Midlands

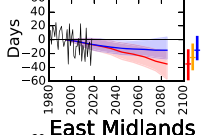

East Midlands

length

RCP6.0 Probabilistic

Growing
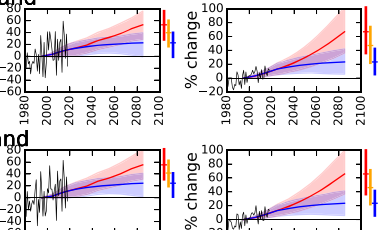

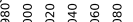

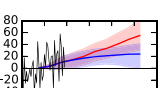

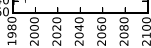
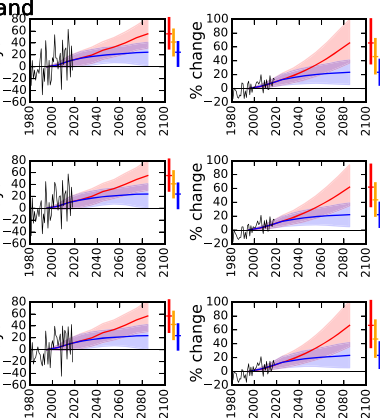

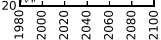
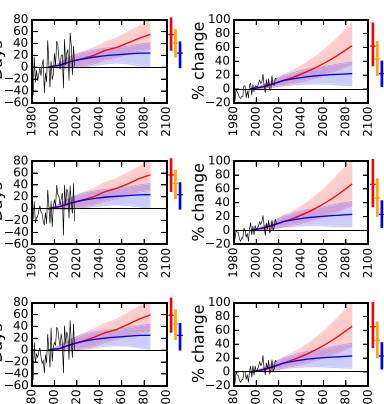

${ }_{60}$ Yorkshire and Humberside
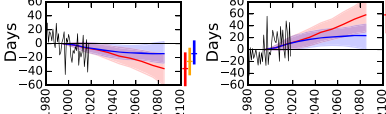

North East Englan

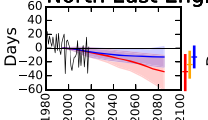

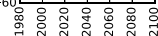

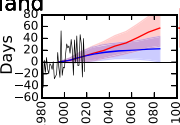

North West England
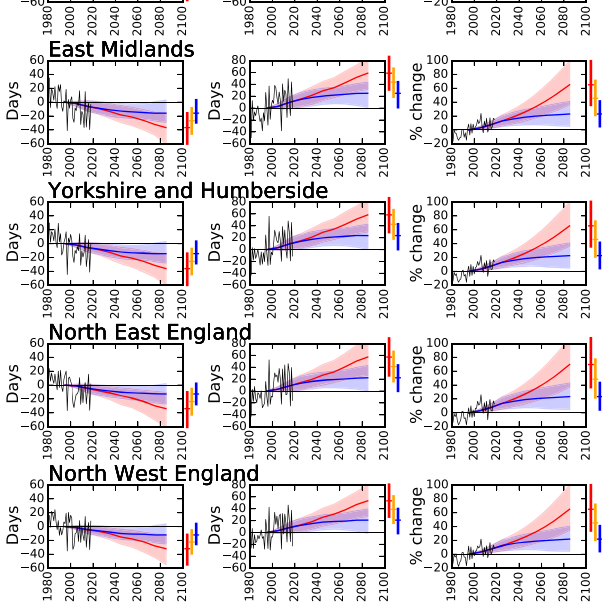

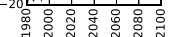

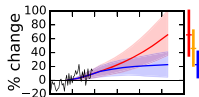

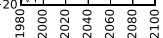

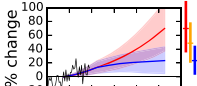

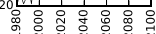

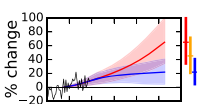

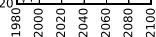

${ }_{60}$ Wales

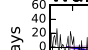

$\widehat{a}^{2}-20$
-40
-60

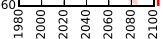

${ }_{60}$ West Scotland
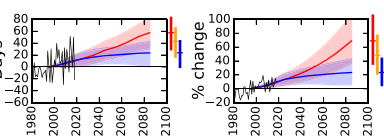

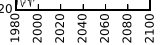

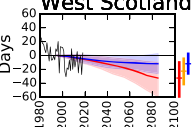
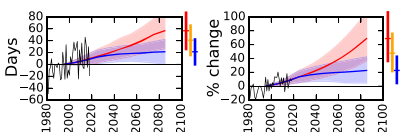

East Scotland

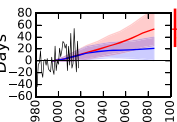

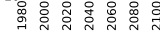

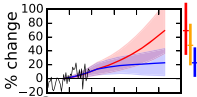

on

${ }_{60}$ North Scotland

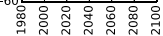

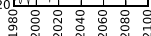

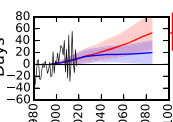

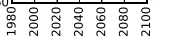

${ }_{60}$ Northern Ireland

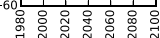

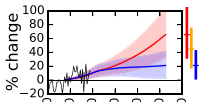

RCP2.6 Probabilistic

Start of Days above

field operations field capacity

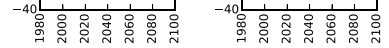
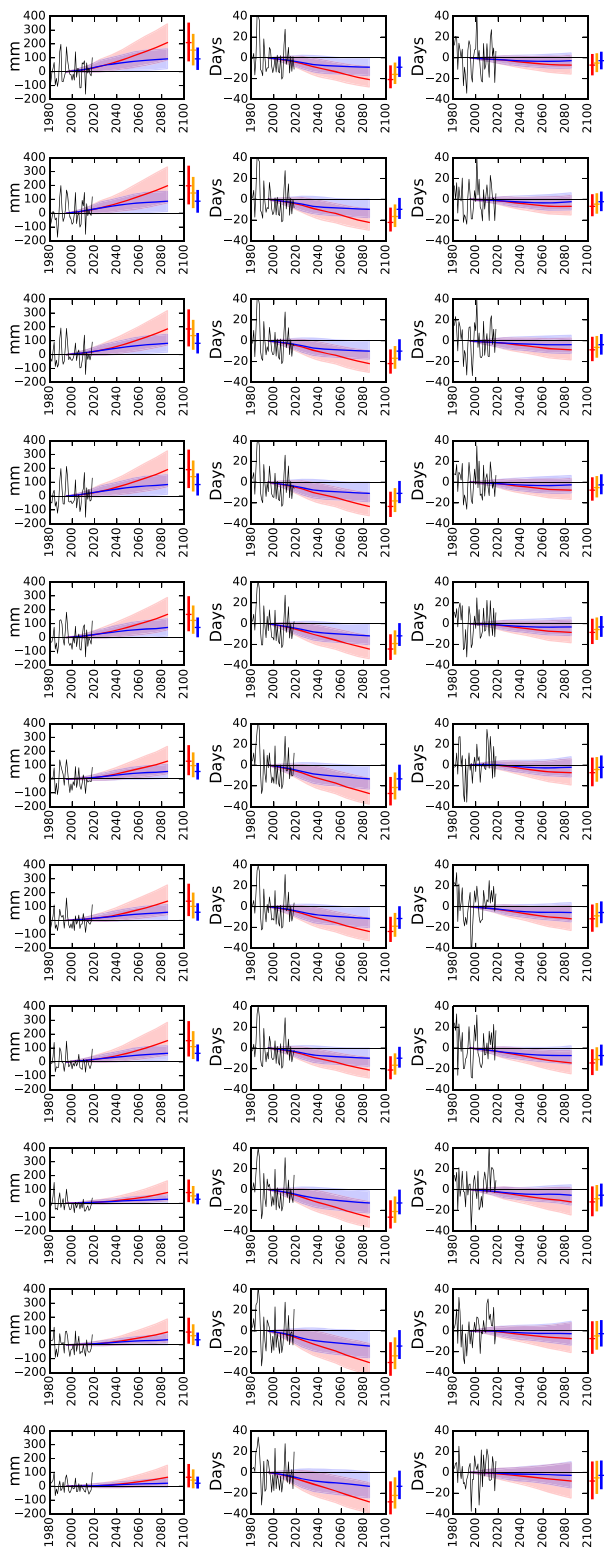

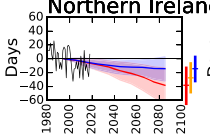
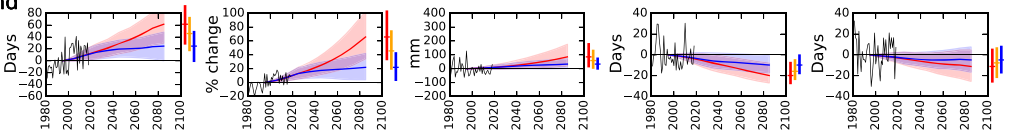
Fig. 4 Indicators of climate resource by region: probabilistic projections, RCP2.6, RCP6.0, and RCP8.5. The 30year mean values are plotted at the central year of the 30 -year period, and the plots show the median plus the 10th to 90th percentile ranges ('low' to 'high'). Annual values from observed data between 1981 and 2018 are shown in black

\section{Change in agro-climate indicators through the twenty-first century}

Figures 4 and 5 show the regional average agro-climate resource, operational, and hazard indicators through the twenty-first century with the three emissions scenarios (data provided in

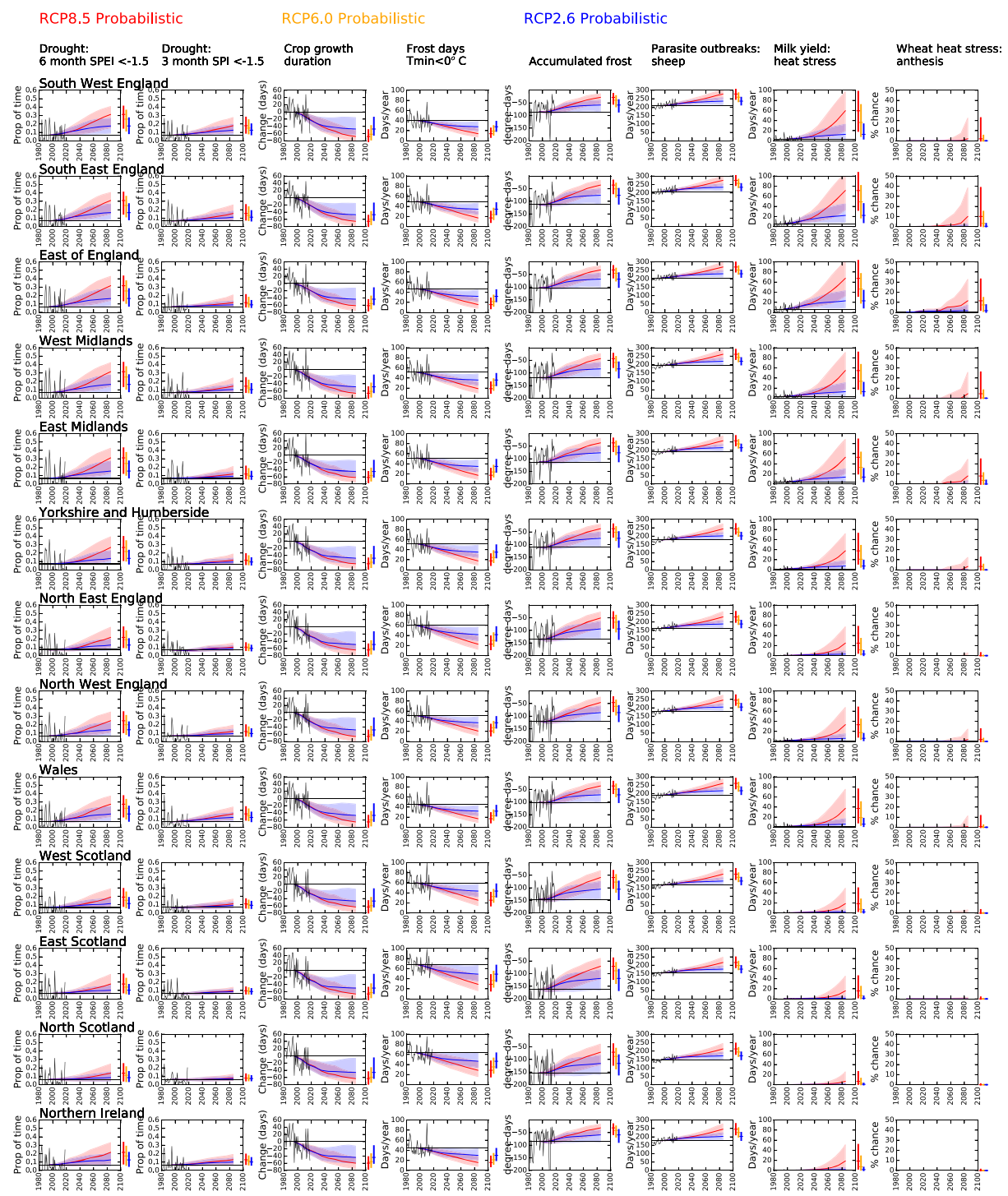

Fig. 5 Indicators of climate hazard by region: probabilistic projections, RCP2.6, RCP6.0, and RCP8.5. The 30year mean values are plotted at the central year of the 30 -year period, and the plots show the median plus the 10th to 90th percentile ranges ('low' to 'high'). Annual values from observed data between 1981 and 2018 are shown in black 
Supplementary Material). The plots show the 30 -year means with the UKCP18 projections and, with the exception of the wheat heat stress indicator, annual values for the period 1981 to 2018 calculated from the HadUK-Grid observations. The shaded areas for each projection represent the effects of uncertainty in the change in climate for that forcing: values for individual years will of course be outside this uncertainty range. The plots show the effect of climate change on the mean, and a comparison between the observed annual values and projections for change in the mean give an indication of the future occurrence of 'extreme' years. The plots for the resource and operational indicators (Fig. 4) show change relative to the 1981-2010 mean, whilst the hazard indicators (with the exception of crop growth duration) show absolute values (Fig. 5).

The pattern of variability in each indicator across the UK is illustrated in Fig. 6, which shows the median estimate of the indicators averaged over the period 2071-2100 with the high RCP8.5 emissions (similar maps for 2041-2070 are presented in Supplementary Material). Figure 7 and Table 3 show the average indicators for the four nations of the UK.

Together, the plots show substantial changes in most of the agro-climate indicators across the UK. Changes are smaller with the lowest RCP2.6 emissions, but even here, there will be agriculturally relevant changes to climate. To the 2040s at least, there is little difference between the three emissions scenarios. For most of the indicators, year-to-year variability is large compared with the climate change trend in the mean.

With the highest emissions, the start of the growing season is brought forward by between 30 and 50 days by the 2080s in southern England - a change of approximately 3 to 5 days per decade. The rate of change is slightly greater in northern England and Scotland. The growing season would be between 40 and 80 days longer by the 2080s, an increase of 4-8 days per decade. Growing degree days increase by between 4 and $10 \%$ per decade, meaning that they could double by the 2080 s. For all three of these indicators, the observed trend over the period 1981 to 2018 is broadly consistent with the climate change trend (and the observed trend in growing degree days is the same as in Kendon et al. 2019b).

The potential soil moisture deficit increases very substantially across the UK. The date for the start of field operations (Tsum200) is between 8 and 20 days earlier in the south by the 2080s, and 10 to 40 days earlier in the north. The number of days with soils at field capacity decreases through the twenty-first century, primarily due to soils being drier for later into autumn (Rivington et al. 2013; see also Supplementary Material). This is despite the projected general increase in autumn rainfall (Fig. 2), and occurs because greater evaporation means soil moisture deficits persist for longer into autumn. The greatest absolute change is in upland regions (typically unimproved grassland) where potential evaporation in late spring and early autumn is currently similar to rainfall: higher potential evaporation and lower rainfall therefore increases soil moisture deficits considerably. The detailed projected changes in days with wet soils vary with soil type (Supplementary Material). The reduction in wet soil days in autumn and annually is less with sandy soils and shallow soils. For these three indicators, there is little apparent trend in the observations.

Drought frequency (expressed as the proportion of time in drought) increases across the whole of the UK, with the greatest increases in the south. The increase in drought frequency is greater with the SPEI indicator because this incorporates the effect of increased potential evaporation, and by the 2080 s, severe drought conditions could occur around $30 \%$ of the time compared with $6.7 \%$ now. Crop growth duration (the time to accumulate reference period growing degree days) decreases across the UK, but the rate of change slows after the 2050s: this trend is consistent with the observations. The number of days with air frost decreases 
Median of Probabilistic RCP8.5 projections 2071-2100

Start of growing season Change in days

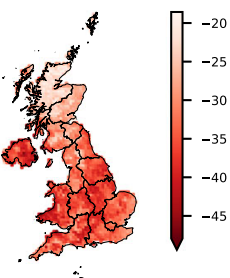

Start of field operations Change in days

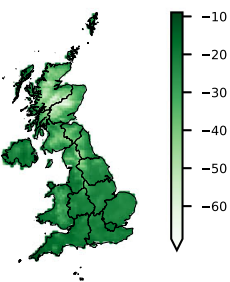

Accumulated frost Change in ${ }^{\circ} \mathrm{C}$-days

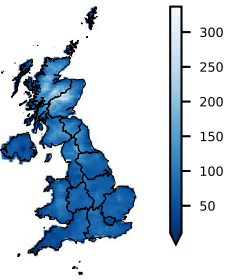

Frost days Change in days

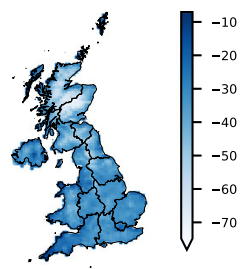

Growing season length Change in days

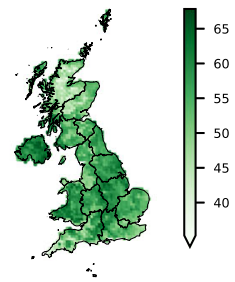

Days with

soil moisture $>$ field capacity Change in days

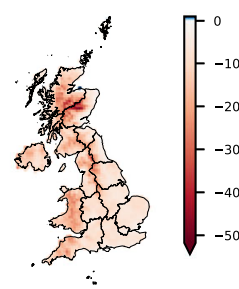

Sheep parasite danger Change in days

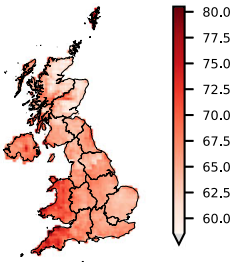

$\therefore$

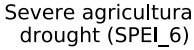
drought (SPEI_6)
proportion of time

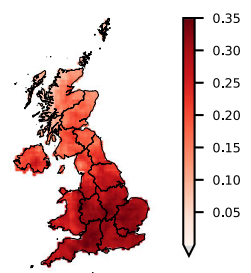

Growing degree days $\%$ change

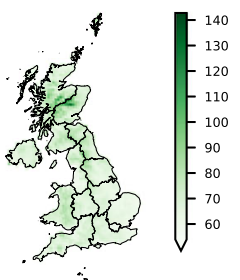

Potential Soil Moisture Deficit Change in $\mathrm{mm}$

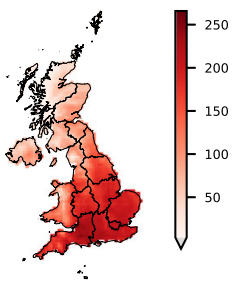

Milk yield: heat stress $\quad \begin{gathered}\text { Wheat heat stress (anthesis) } \\ \text { Change in days }\end{gathered}$
$\%$ chance

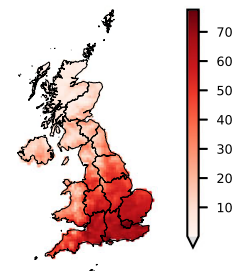

Severe agricultura
drought (SPI_3) proportion of time

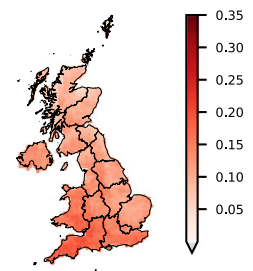

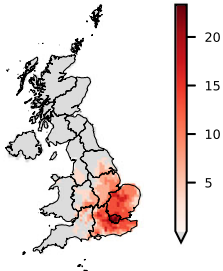

Crop growth duration Change in days

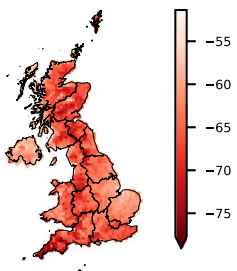

Fig. 6 Variation in agro-climate indicators across the UK with high (RCP8.5) emissions over the period 20712100: median of the probabilistic projections. The maps show the 30-year mean indicator (\% chance over 30 years for the wheat heat stress indicator)

significantly through the century, again consistent with observations. Accumulated frost reduces meaning an increased risk that pests can survive winter, and in southern England may be almost eliminated by the end of the century. The number of days with temperatures suitable for sheep parasites increases across the UK, by up to 35 days by the 2050s: the greatest increase is in Wales and the west and south of England. There is a very large increase in the 
RCP8. 5 Probabilistic

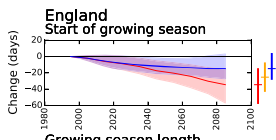

Growing season length
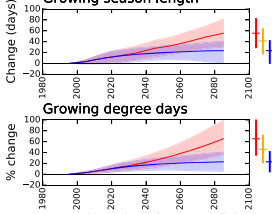

Potential Soil Moisture Déficit

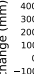

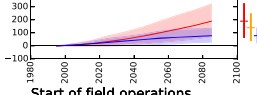

ज. Start of field operations

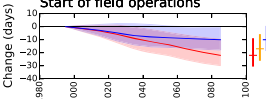

Days above field capacity

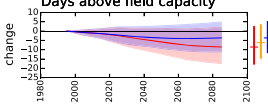

Drought: 6 month SPEI $<-1.5$

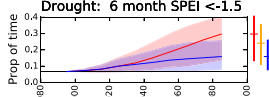

Drought: 3 month SPI $<-1.5$

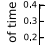

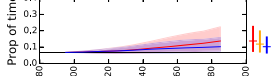

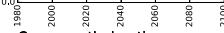

Crop growth duration
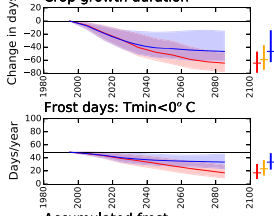

Accumulated frost

吾 -5

岕 -150

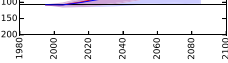

Sheep parasite danger

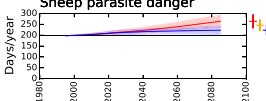

Milk yield: heat stress
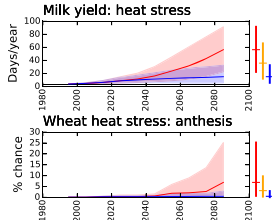

RCP6.0 Probabilistic
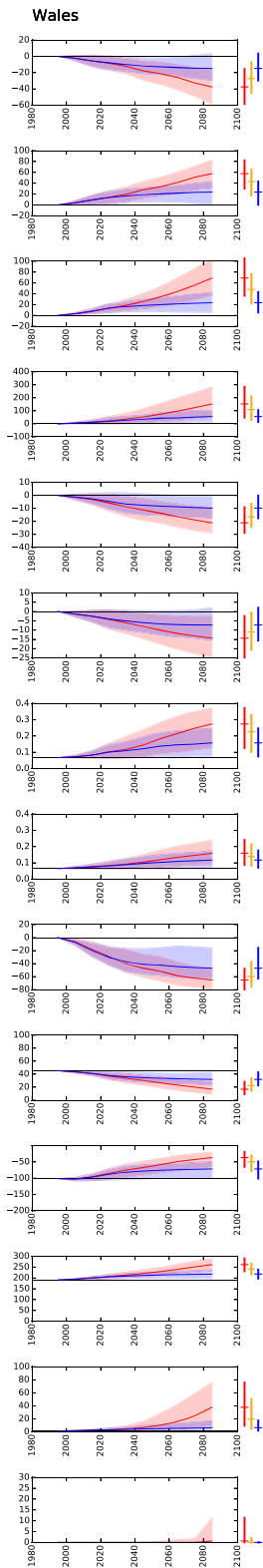

RCP2.6 Probabilistic
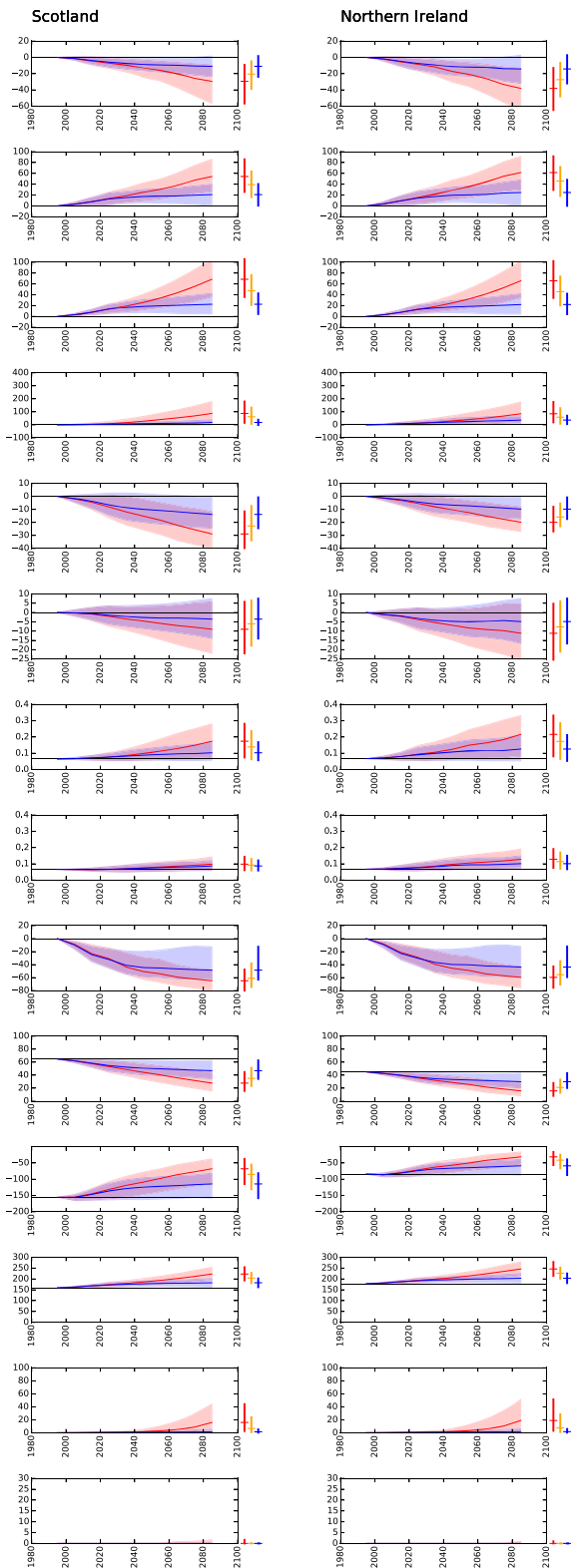

Fig. 7 Indicators of agri-climate hazard and resource: national scale: probabilistic projections, RCP2.6, RCP6.0, and RCP8.5. The mean values are plotted at the central year of the 30-year period, and the plots show the median plus the 10th to 90th percentile ranges ('low' to 'high')

number of days causing heat stress for dairy cattle across southern England, particularly with high emissions. This increase is proportionally greater than for the sheep parasite indicator because the effective temperature threshold is much higher. Finally, extreme temperatures during wheat anthesis remain extremely rare until the 2050s (consistent with Harkness et al. 


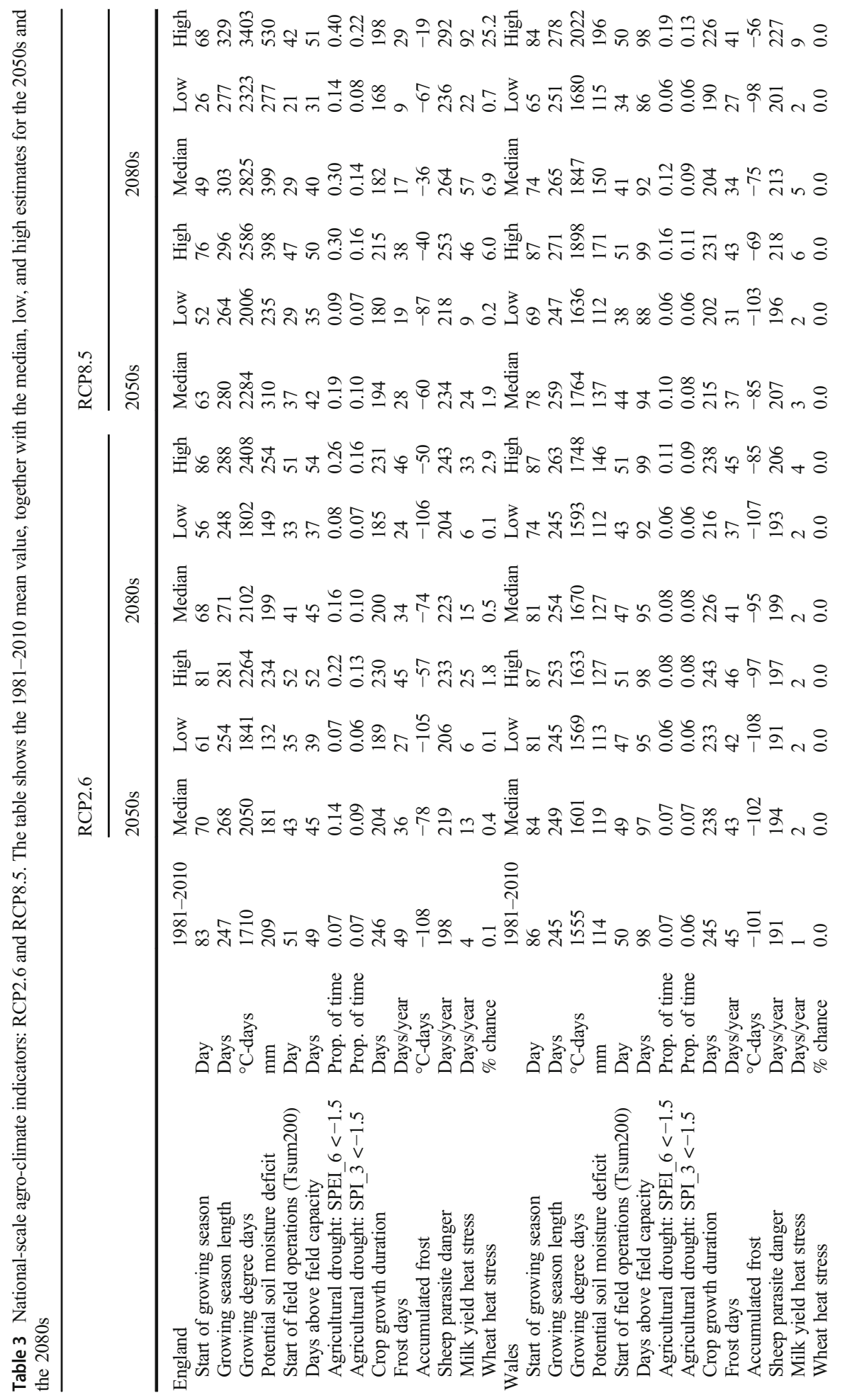




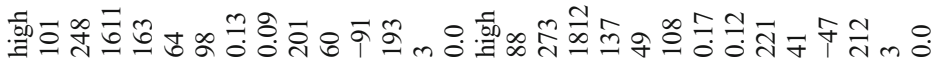

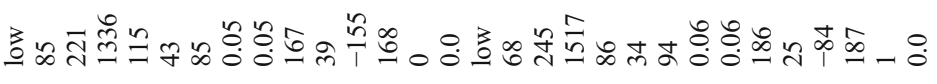

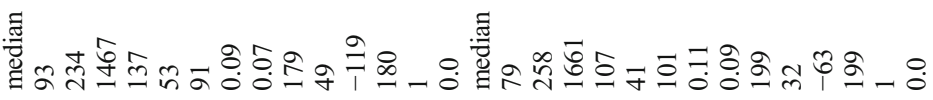

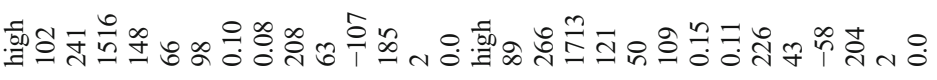

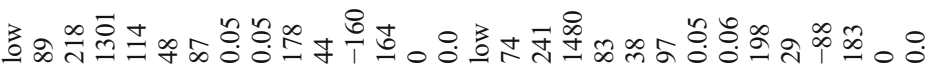

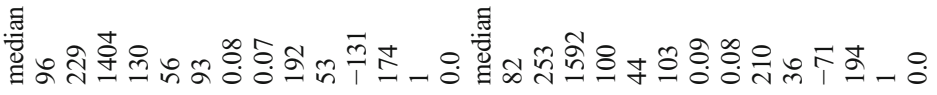

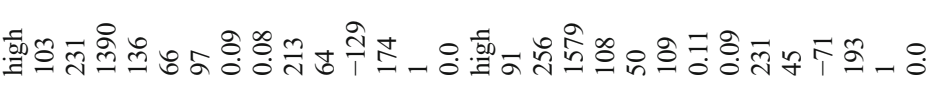

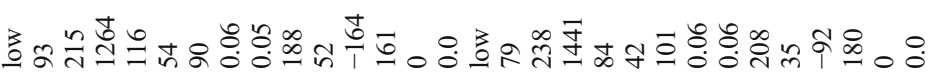
燢

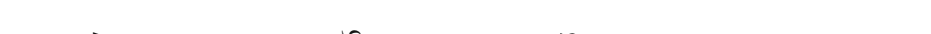
㫮苗ส

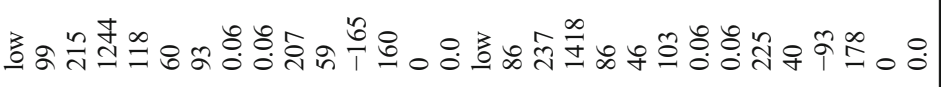

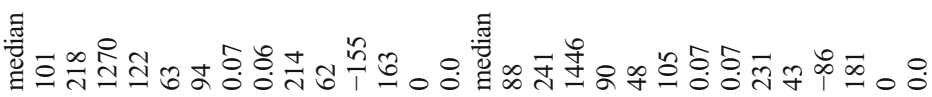
윤

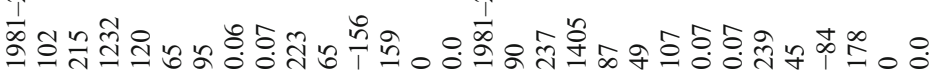
妾兽

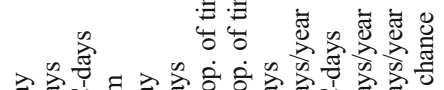

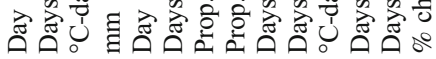

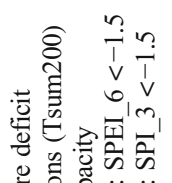


2020), after which they become more likely in eastern England by the 2050s and across most of the south and east by the 2080s.

Figures 4 and 5 compare the climate change trend in the mean with annual variability, and this gives an indication of changes in the future occurrence of 'extreme' years - although precise quantification depends of course on the definition of 'extreme'. However, climate change also affects year to year variability around the mean for some indicators (Figs. 8 and 9). This occurs even though the delta approach used here to construct climate scenarios does not significantly affect year to year variability in weather, because most of the indicators are based on exceedance of some threshold. Variability in the start of the growing season and growing season length increases slightly, and there is a relatively greater increase in the variability in growing degree days. In contrast, the variability in the start of field operations reduces over time - it becomes more consistent - but there is little change in the average potential soil moisture deficit or number of days with wet soils. Drought variability increases as droughts become more frequent, then decreases - particularly for SPEI - as droughts begin to occur in most years. There is little change in the variability in frost days, but the variation in accumulated frost reduces as totals become smaller. There is a slight increase in variability in the number of days suitable for sheep parasites, but a greater increase in the year-to-year variability in days with heat stress for dairy cattle.

The plots show that whilst there is a broad agreement of the direction of change in a region for a given indicator, there can be considerable uncertainty in the magnitude of change by the end of the twenty-first century and the rate of change. For the temperature-based indicators, it is generally influenced by how rapidly temperatures increase for a given rate of change in emissions and this is strongly influenced by the sensitivity of the climate system to forcing. This is typically characterised by Equilibrium Climate Sensitivity (ECS), and the latest generations of climate models tend to have higher ECS values than previous generations (Meehl et al. 2020). For the rainfall-based indicators (soil wetness and drought), the uncertainty is largely driven by uncertainty in the magnitude of the change in rainfall which is itself due to differences in the atmospheric dynamic response to forcing between models.

The probabilistic projections combine information from the two global strandsHadGEM3 and CMIP5 - and the two strands span different parts of the uncertainty range (see Supplementary Material). The HadGEM3 projections have a greater rate of increase in temperature for a given forcing than the CMIP5 projections (they have a higher ECS), and also tend to generate larger increases in winter rainfall and larger reductions in summer rainfall. The HadGEM3 projections therefore show larger changes in agro-climate indicator-and are therefore at the top of the uncertainty ranges in Figs. 4, 5, and 7-whilst the CMIP5 ensemble tends to show smaller changes.

\section{Conclusions and implications for agriculture in the UK}

Agriculture in the UK is currently facing a series of challenges, including Brexit (altering not only relationships with European and international markets but also government policy priorities), changes in customer preferences, public and policy perceptions of the role of agriculture in the landscape, and increasing concerns with environmental sustainability and stewardship. This paper shows, using a range of indicators relevant to the UK, that climate change adds materially to these challenges by altering the climatic conditions that farmers and agricultural systems have become accustomed to. The information presented here can be used 
RCP8.5 Probabilistic

Start of

growing season Growing season

${ }_{40}$ South West England
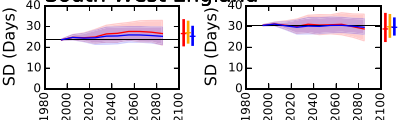

South East England

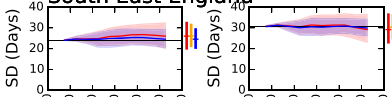

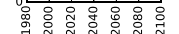

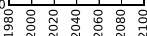

RCP6.0 Probabilistic

Growing
degree days
RCP2.6 Probabilistic

Start of
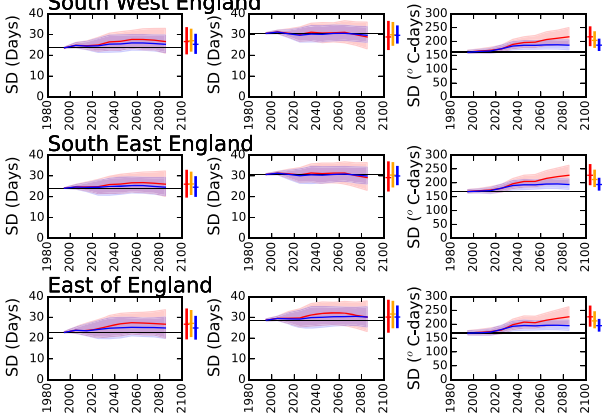

field capacity
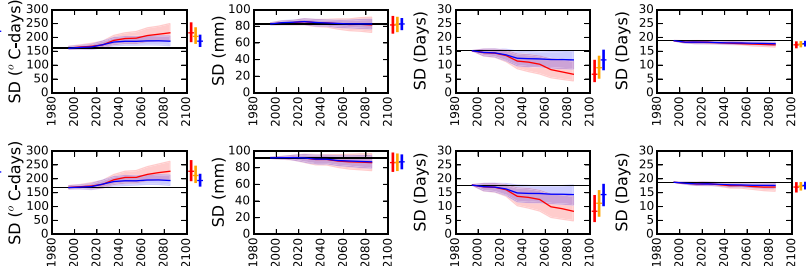

${ }^{40}$ West Midlands
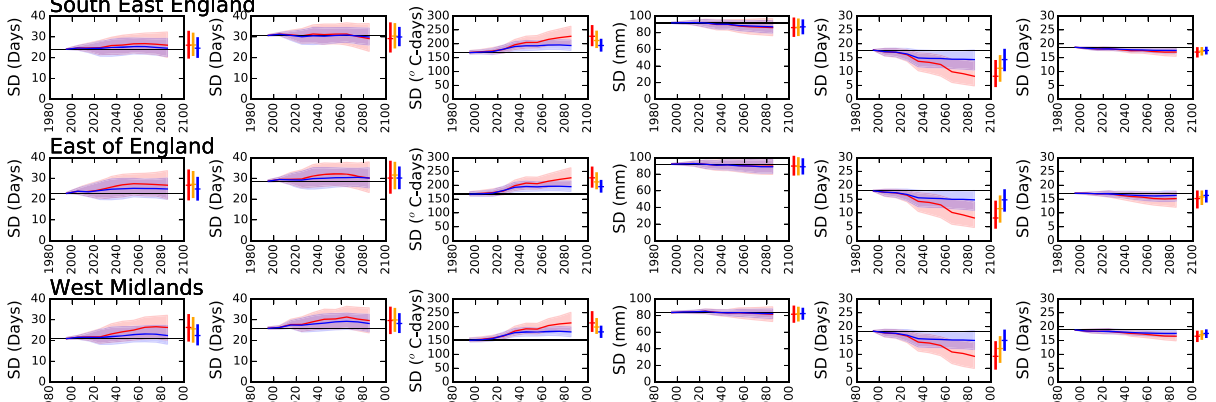

${ }_{40}$ East Midilands
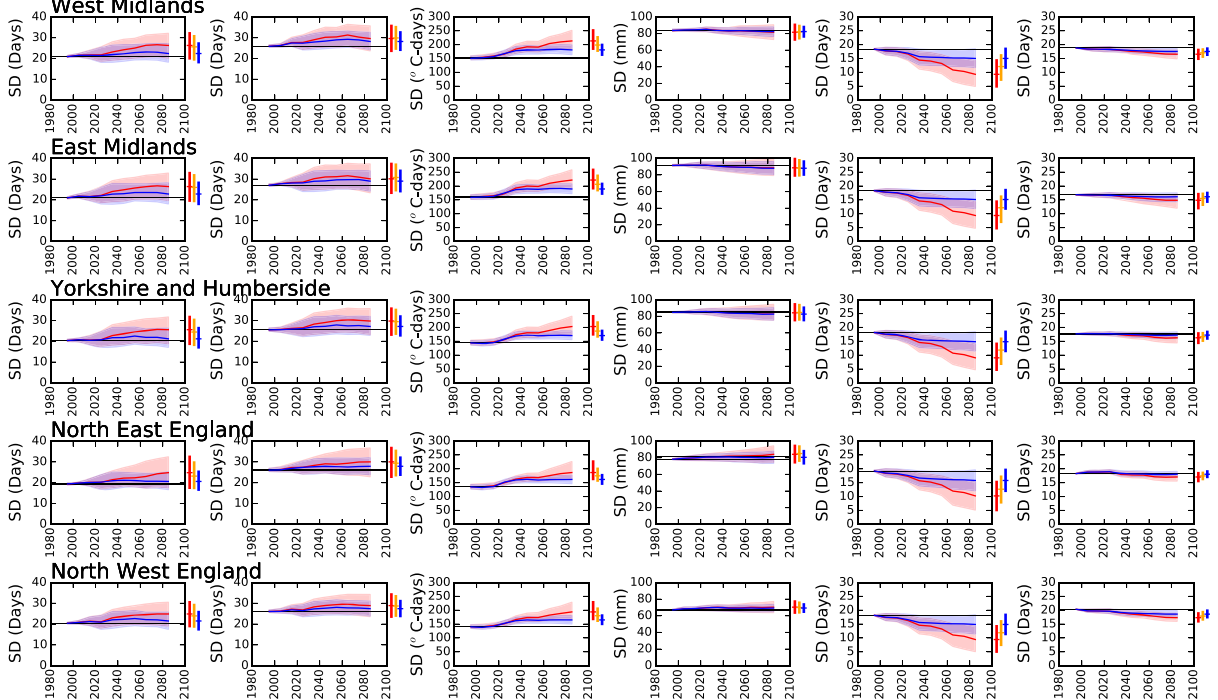

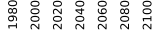

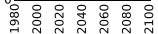
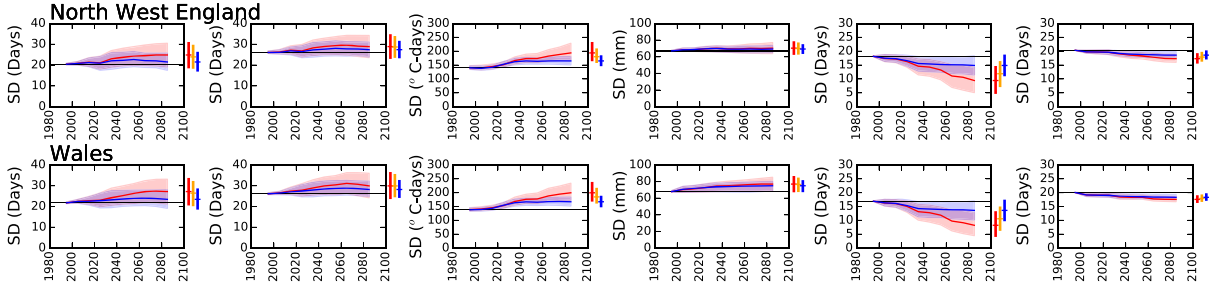

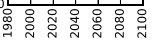
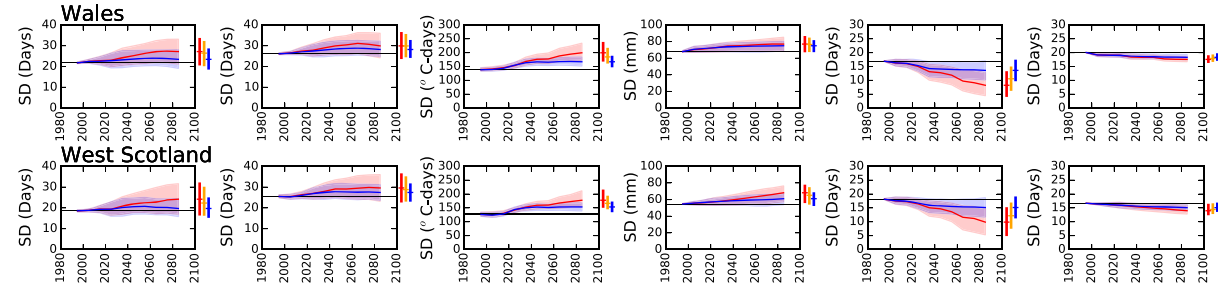

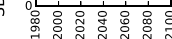
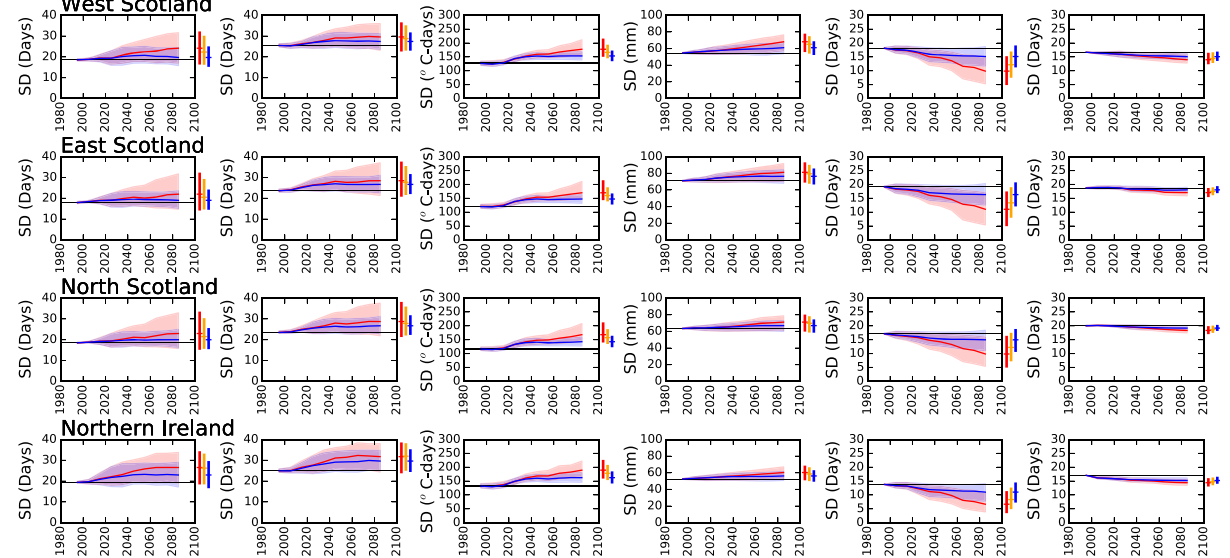
Fig. 8 Standard deviation of the indicators of climate resource by region: probabilistic projections, RCP2.6, RCP6.0, and RCP8.5. The standard deviation over 30 years is plotted at the central year of the 30-year period, and the plots show the median plus the 10th to 90th percentile ranges ('low' to 'high')

\section{RCP8.5 Probabilistic}

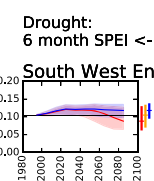

Drought: $\quad$ Crop growth

Crop grow
duration
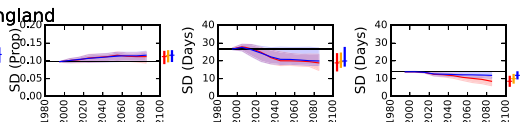

RCP2.6 Probabilistic

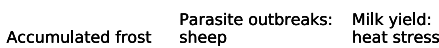

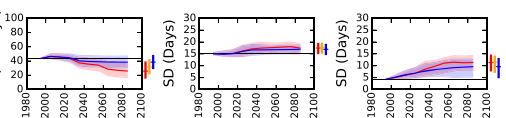

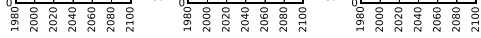
South East England

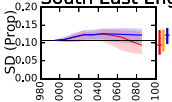

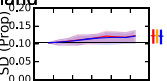

领 ${ }^{40}{ }^{20}+1$

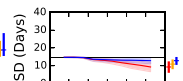

r

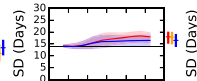

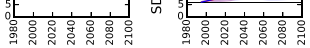
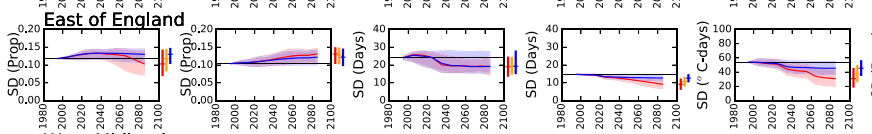

n

West Midlands
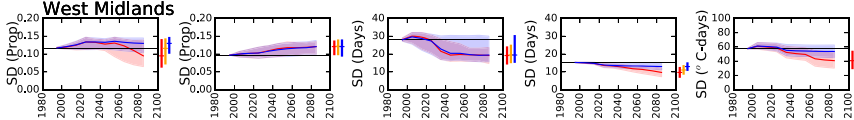

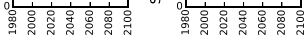
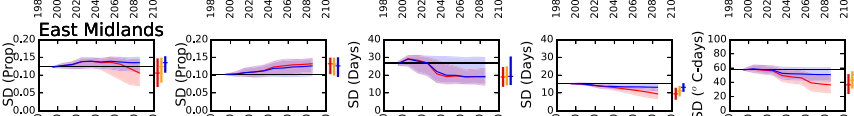

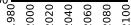

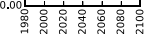

0.20 Yorkshire and Hymberside
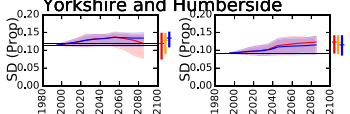

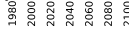
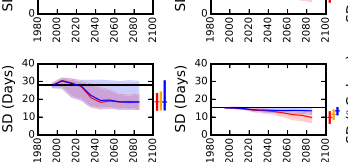

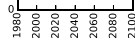

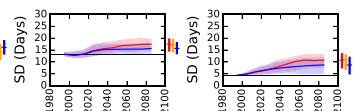

North East England
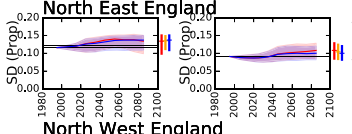

0.20 North West England

\begin{tabular}{ll}
\hline \\
0.20
\end{tabular}

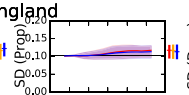

0.20 Wales

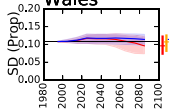

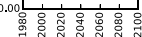
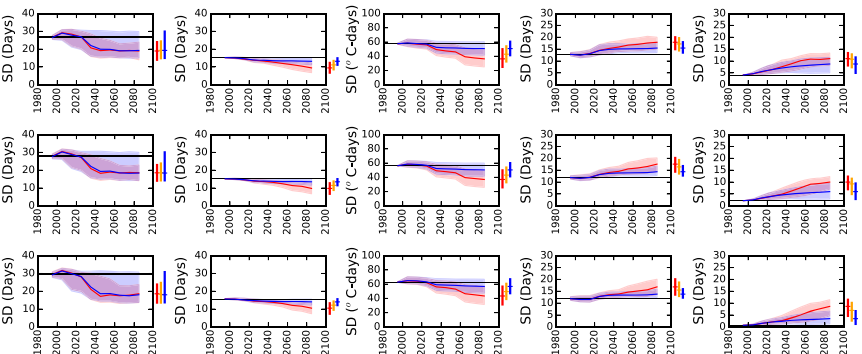

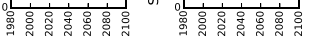

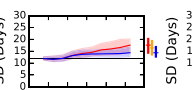

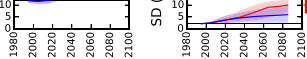
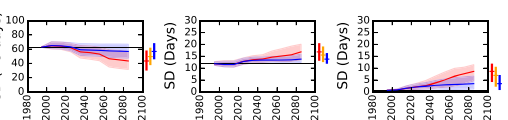

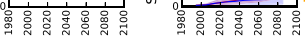
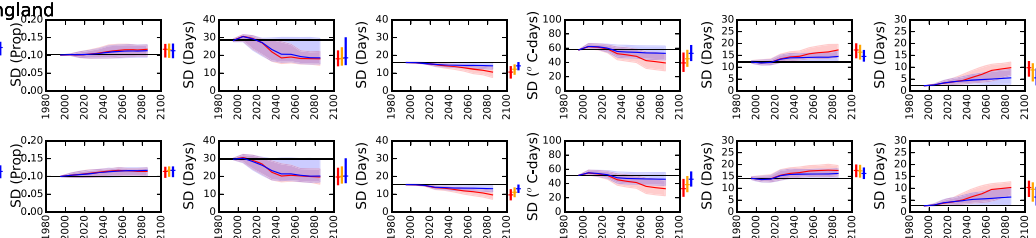

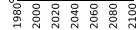
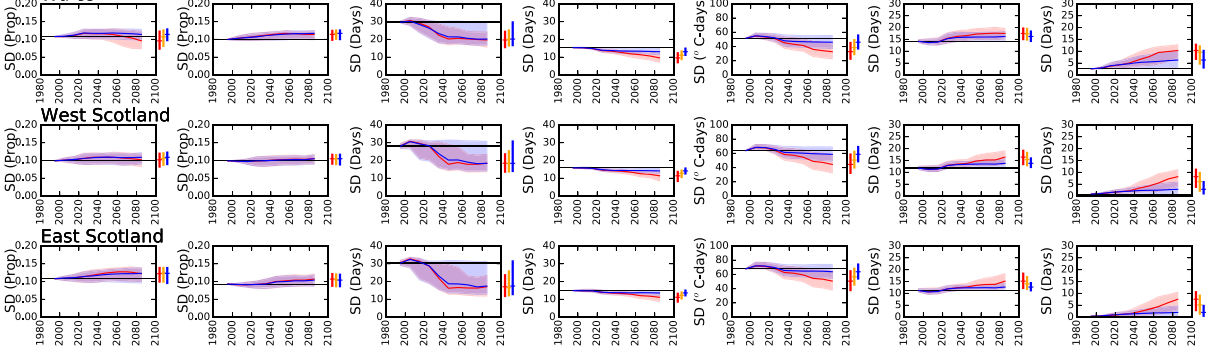

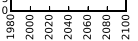

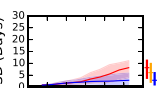

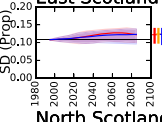

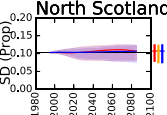
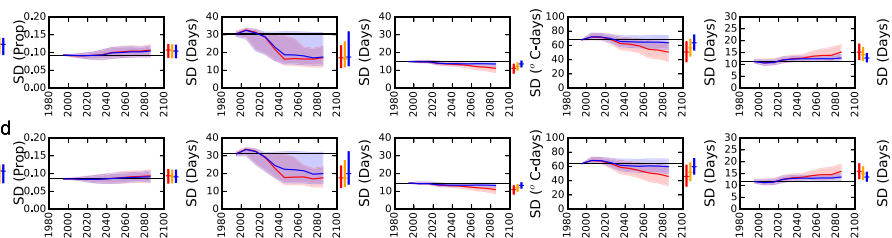

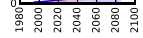
Northern Ireland
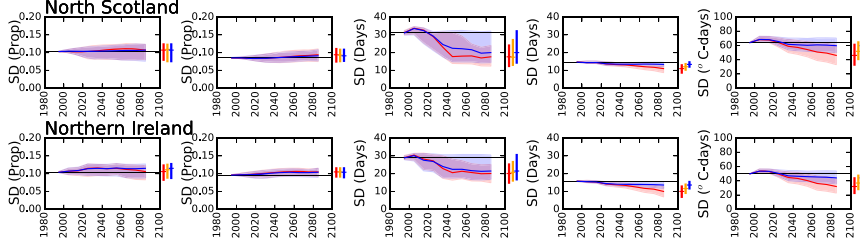

Fig. 9 Standard deviation of the indicators of climate hazard by region: probabilistic projections, RCP2.6, RCP6.0, and RCP8.5. The standard deviation over 30 years is plotted at the central year of the 30 -year period, and the plots show the median plus the 10th to 90th percentile ranges ('low' to 'high') 
to inform high-level assessments of potential changes to agriculture in the UK and implications for adaptation and mitigation strategy. It provides the context for more tailored sector- or place-focused adaptation and resilience planning - for example based around thresholds for critical change - and highlights areas for further investigation. Although there are differences in the detail of the climate projections and indicators used and spatial scale, the results here are broadly qualitatively consistent with those of previous studies of agro-climatic indicators in the UK - but they cover a wider range of indicators than these previous studies.

There are two major caveats with the approach used. First, the delta method used to construct future climates preserves the current year-to-year variability in climate (although variability in the indicators can change) and therefore does not incorporate the extra potential effects of changes in climatic variability from year to year or day to day. Second, the approach uses generalised indicators which are proxies for agricultural impacts, rather than attempt to estimate actual impacts using site- and crop-specific metrics, and most of these indicators characterise changes in the mean rather than the occurrence of extremes. In practice, adverse impacts in any 1 year may be very dependent on the precise timing or characteristics of extreme weather events. The projected effects of climate change are here characterised by changes in the multi-year mean (with the exception of the wheat heat stress indicator), but other threshold-based indicators representing potential changes in 'extreme' years can be readily calculated from the underlying annual values once critical thresholds are defined.

The results show that there will be substantial changes in the climate resource and hazard across the UK during the twenty-first century if emissions continue to follow a high trajectory, and there will still be some changes if emissions reduce to achieve international climate policy targets. Future climate conditions for agriculture will be very different from current conditions. Growing seasons will lengthen, crop growth will be accelerated, and both drought and heat risks will increase - although damaging high temperatures for wheat are unlikely to become significant until the 2050s. Soils will generally become drier in autumn (despite increases in autumn rainfall), although there will be less change in winter and spring. Opportunities will arise for new crops. Some changes are broadly consistent across the UK, but others are more geographically variable. Increases in heat, drought, and soil moisture deficit risks are greatest in the south and east of England, but the greatest increase in sheep parasite danger is in the west. For most of the indicators, the trend over the twenty-first century is small compared with year-to-year variability, but the underlying trends will alter the frequency of low and high extremes.

The link between agro-climate indicators and future yields, however, varies between crop types and management practices. Most significantly, the yield of C3 crops-which include wheat, barley, and grass - is affected by atmospheric $\mathrm{CO}_{2}$ concentration, and this may offset the adverse effects of increased water stress (as shown for example in crop modelling studies by Semenov (2009), Yawson et al. (2016), Qi et al. (2018), Ritchie et al. (2019), and Harkness et al. (2020)). Changes in $\mathrm{CO}_{2}$ concentration have little effect on the productivity of $\mathrm{C} 4$ plants - including maize - so they will be more directly affected by changes in climate. Reductions in crop development times may reduce yields, but at the same time may mean that crops mature before being exposed to drought or heat stress (Semenov 2009; Harkness et al. 2020). Changes in climate and $\mathrm{CO}_{2}$ concentrations will also affect the growth of weeds. Meanwhile, farmers will plant new crops and cultivars in response to changing conditions.

Whilst the effects of changes in climate resource and hazard on actual productivity are therefore difficult to quantify, it is clear that climate change will tend to increase the frequency of three of the 
most challenging weather events affecting crop growth and livestock welfare and productivityheat stress, drought, and (not explicitly considered here; see Kay et al. 2014) flood. Heat stress increases most significantly in southern England, whilst drought stress increases more widely across all but the western parts of the UK. On average, water-logging may become less likely in the future, improving access to land, but the changes will be greatest in autumn rather than spring and wet years with wet soils in late spring will still occur. This general increase in the likelihood of challenging conditions through the year will not only affect actual productivity, but will also affect farmer decisions about what to plant and what infrastructure is needed.

Measures to enhance resilience to change in the mean and the likelihood of extreme events in the agricultural sector operate at two levels. At the farm level, the farmer has three broad categories of measure: (i) use new crops, cultivars, varieties or breeds, (ii) change practices, or (iii) diversify. The farmer may chose, for example, to plant a crop or a cultivar, or use a breed of livestock, that is less vulnerable to drought or heat stress. This may involve changing from one broad type of farming to another, for example from arable to livestock, but this may involve substantial transaction costs relating to machinery, storage, labour, and skills. Changing practices may involve altering the timing of actions, using irrigation, or using seasonal forecasts to inform planting decisions. Diversification involves broadening the range of activities to lessen the farm-scale effects of adverse conditions (Gaudin et al. 2015; Urruty et al. 2016; Dardonville et al. 2020).

At the agricultural system level, there are several potential categories of measure. One is to develop new cultivars or varieties that are suitable for changed climatic conditions, and another is develop new practices appropriate for hotter and drier climates - for example improved irrigation or livestock housing. Improvements in seasonal weather forecasting might help farmers make planting and management decisions, given an increased risk of damaging events during the growing season.

Farm and system level measures to enhance resilience, however, need to be embedded within an enabling policy framework. Following its departure from the European Union and its Common Agricultural Policy, the UK government is developing a new policy approach to agriculture. A new Agriculture Bill was submitted to Parliament in January 2020, which seeks to support farming and the rural economy and landscape. It places great emphasis on Environmental Land Management, aiming to refocus public support to encourage environmentally sustainable behaviours and practices. However, whilst climate change is widely cited in policy documents (e.g. Defra 2020b), the discussion is limited to climate mitigation and the reduction of greenhouse gas emissions. In principle, the mechanisms currently proposed to enhance farm resilience (through grants for investment) could be used to adapt to a changing climate, although this is not explicitly mentioned.

All these farm and system scale measures to enhance resilience need to be informed by projections of how agricultural conditions may change in the future, and this paper presents a consistent set of projections of a range of relevant indicators using the latest climate projections. The general direction of change is clear - with the notable exception of days with wet soils - but the rate and magnitude of change is uncertain. To the 2040s, at least the projected changes do not depend on assumptions about future emissions, and the range in possible changes in a place is driven by uncertainty in precisely how climate changes across the UK in response to increases in greenhouse gas emissions. For the temperature-based indicators, this largely reflects uncertainty in the overall sensitivity of the climate system to change in forcing, whilst for the rainfall-based indicators, it reflects uncertainty in changes in weather patterns bringing rainfall to the UK. This uncertainty is important because it implies that measures to enhance resilience need explicitly to take into account uncertainty in how climate will change: measures that can cope with a central estimate of change in mean or variability may not be sufficient to cope with projected plausible large changes. 
Supplementary Information The online version contains supplementary material available at https://doi.org/ 10.1007/s10584-021-03054-8.

Acknowledgements We thank the anonymous reviewers for the helpful comments.

Code availability The analysis used custom code, which can be made available on request.

Author contributions NWA conceived the study, AF constructed the climate scenarios, and NWA and AF wrote the paper.

Funding This research was funded through the UKRI Climate Resilience programme (Grant NE/S016481/1).

Data availability Regional and national data are provided in Supplementary Material.

\section{Declarations}

Conflict of interest The authors declare no competing interests.

Open Access This article is licensed under a Creative Commons Attribution 4.0 International License, which permits use, sharing, adaptation, distribution and reproduction in any medium or format, as long as you give appropriate credit to the original author(s) and the source, provide a link to the Creative Commons licence, and indicate if changes were made. The images or other third party material in this article are included in the article's Creative Commons licence, unless indicated otherwise in a credit line to the material. If material is not included in the article's Creative Commons licence and your intended use is not permitted by statutory regulation or exceeds the permitted use, you will need to obtain permission directly from the copyright holder. To view a copy of this licence, visit http://creativecommons.org/licenses/by/4.0/.

\section{References}

Arnell NW et al (2021) Changing climate risk in the UK: a multi-sectoral analysis using policy-relevant indicators. Clim Risk Manag 31:100265

Bachmair S et al (2018) How well do meteorological indicators represent agricultural and forest drought across Europe? Environ Res Lett 13:034042

Brown I et al (2011) Climate change, drought risk and land capability for agriculture: implications for land use in Scotland. Reg Environ Chang 11:503-518

Brown I et al (2016) UK climate change risk assessment evidence report: chapter 3, natural environment and natural assets. Report prepared for the Adaptation Sub-Committee of the Committee on Climate Change, London

CEH (2017) Land Cover Map 2015 UK Centre for Ecology and Hydrology

Cho K et al (2012) Winter wheat yields in the UK: uncertainties in climate and management impacts. Clim Res 54:49-68

Copernicus Climate Change Service (C3S) (2017) ERA5: Fifth generation of ECMWF atmospheric reanalyses of the global climate. Copernicus Climate Change Service Climate Data Store (CDS), 30/07/2019. https://cds. climate.copernicus.eu/cdsapp\#!/home

Craufurd PQ, Wheeler TR (2008) Climate change and the flowering time of annual crops. J Exp Bot 60:2529-2539

Daccache A et al (2012) Climate change and land suitability for potato production in England and Wales: impacts and adaptation. J Agric Sci 150:161-177

Dardonville $\mathrm{M}$ et al (2020) Influence of diversity and intensification level on vulnerability, resilience and robustness of agricultural systems. Agric Syst 184:102913

Defra (2020a) Agriculture in the United Kingdom 2019. Department for Environment, Food and Rural Affairs, Department of Agriculture, Environment and Rural Affairs (Northern Ireland), Welsh Government Knowledge and Analytical Services, and Scottish Government Rural and Environmental Science and Analytical Services 
Defra (2020b) Farming for the future: policy and progress update February 2020. Department for Environment, Food and Rural Affairs PB 14610

Deryng D et al (2014) Global crop yield response to extreme heat stress under multiple climate change futures. Environ Res Lett 9:034011

Dewar AM, Carter N (1984) Decision trees to assess the risk of cereal aphid (Hemiptera: Aphididae) outbreaks in summer in England. Bull Entomol Res 74:387-398

Dunn RJH et al (2014) Analysis of heat stress in UK dairy cattle and impact on milk yields. Environ Res Lett 9:064006

Fezzi C et al (2014) Valuing provisioning ecosystem services in agriculture: the impact of climate change on food production in the United Kingdom. Environ Resour Econ 57:197-214

Fodor N et al (2018) Spatially explicit estimation of heat stress-related impacts of climate change on the milk production of dairy cows in the United Kingdom. PLoS One 13(5):e0197076

Gaudin AMC et al (2015) Increasing crop diversity mitigates weather variations and improves yield stability. PLOS ONE 10(2):e0113261

Gobin A (2018) Weather related risks in Belgian arable agriculture. Agric Syst 159:225-236

Harding AE et al (2015) Agro-meteorological indices and climate model uncertainty over the UK. Clim Chang 128:113-126

Harkness C et al (2020) Adverse weather conditions for UK wheat production under climate change. Agric For Meteorol 282-283:107862

Haro-Monteaguodo D, Daccache A, Knox J (2017) Exploring the utility of drought indicators to assess climate risks to agricultural productivity in a humid climate. Hydrol Res 49(2):539-551

Hatfield JL et al (2011) Climate impacts on agriculture: implications for crop production. Agron J 103:351-370

Hatfield JL et al (2020) Indicators of climate change in agricultural systems. Clim Chang 163:1719-1732

Hollis D et al (2019) HadUK-grid - a new UK dataset of gridded climate observations. Geosciences Data Journal 6:151-159

Jones L et al (2020) Climate driven threshold effects in the natural environment. Report to the UK Climate Change Committee May 2020

Kay AL et al (2014) Probabilistic impacts of climate change on flood frequency using response surfaces. 1: England and Wales. Reg Environ Chang 14:1215-1227

Keay CA et al (2013) SP1104 the impact of climate change on the capability of land for agriculture as defined by the Agricultural Land Classification. Defra, 139pp

Kendon E et al (2019a) UKCP convection-permitting model projections: science report. Met Office Hadley Centre

Kendon M et al (2019b) State of the UK climate 2018. Int J Climatol 39(suppl. 1):1-55

Knox J et al (2010) Identifying future risks to UK agricultural crop production. Outlook on Agriculture 39:249-256

Lowe JA et al (2018) UKCP18 science overview report. Met Office Hadley Centre, version 2.0

Matthews KB et al (2008) Characterising the agro-meteorological implications of climate change scenarios for land management stakeholders. Clim Res 365:59-75

McKee TB et al (1993) The relationship of drought frequency and duration to time scales. In: Proceedings of the 8th Conference on Applied Climatology. American Meteorological Society: Boston, MA, Anaheim, CA, pp. 179-184

Meehl, G.A. et al. (2020) Context for interpreting equilibrium climate sensitivity and transient climate response from the CMIP6 earth system models. Science Advances 6, eaba1981

Met Office (2018) HadUK-grid gridded climate observations on a $12 \mathrm{~km}$ grid over the UK for 1862-2017. Centre for Environmental Data Analysis, 15/07/2019. http://catalogue.ceda.ac.uk/uuid/ dc2efle4f10144f29591c21051d99d39

Murphy JM et al (2019) UKCP18 land projections: science report. Met Office Hadley Centre, version 2.0

Olesen JE, Bindi M (2002) Consequences of climate change for European agricultural productivity, land use and policy. Eur J Agron 16:239-262

Parsons DJ et al (2019) Regional variations in the link between drought indices and reported agricultural impacts of drought. Agric Syst 173:119-129

Qi A et al (2018) Grassland futures in Great Britain - productivity assessment and scenarios for land use change opportunities. Sci Total Environ 634:1108-1118

Ritchie PDI et al (2019) Large changes in Great Britain's vegetation and agricultural land-use predicted under unmitigated climate change. Environ Res Lett 14:114012

Rivington $\mathrm{M}$ et al (2013) Climate change impacts and adaptation scope for agriculture indicated by agrometeorological metrics. Agric Syst 114:15-31

Selvaraju R et al (2011) Climate science in support of sustainable agriculture and food security. Clim Res 47:95-110

Semenov MA (2009) Impacts of climate change on wheat in England and Wales. J R Soc Interface 6:343-350

Stehr N, von Storch H (2009) Climate and society: climate as resource, climate as risk. World Scientific Pub Co Inc, Hackensack

Trnka M et al (2010) Is rainfed crop production in central Europe at risk? Using a regional climate model to produce high resolution agroclimatic information for decision makers. J Agric Sci 148:639-656 
Trnka M et al (2014) Adverse weather conditions for European wheat production will become more frequent with climate change. Nat Clim Chang 4:637-643

Urruty N, Tailliez-Lefebvre D, Huyghe C (2016) Stability, robustness, vulnerability and resilience of agricultural systems. A review. Agron Sustain Dev 36:1-15

Vicente-Serrano S et al (2010) A multi-scalar drought index sensitive to global warming: the standardised precipitation evapotranspiration index - SPEI. J Clim 23:1696-1711

Walsh MK et al (2020) Climate Indicators for Agriculture. USDA Technical Bulletin 1953. Washington, DC. 70 pages. https://doi.org/10.25675/10217/210930

Yawson DO et al (2016) Simulated regional yields of spring barley in the United Kingdom under projected climate change. Climate 4:cli4040054

Publisher's note Springer Nature remains neutral with regard to jurisdictional claims in published maps and institutional affiliations. 